\title{
SALTY :
}

A Hybrid Computer Program for Three-Dimensional Heat Transfer from a Discrete Source

\author{
R. S. Stone \\ O. W. Burke
}




\section{DISCLAIMER}

This report was prepared as an account of work sponsored by an agency of the United States Government. Neither the United States Government nor any agency Thereof, nor any of their employees, makes any warranty, express or implied, or assumes any legal liability or responsibility for the accuracy, completeness, or usefulness of any information, apparatus, product, or process disclosed, or represents that its use would not infringe privately owned rights. Reference herein to any specific commercial product, process, or service by trade name, trademark, manufacturer, or otherwise does not necessarily constitute or imply its endorsement, recommendation, or favoring by the United States Government or any agency thereof. The views and opinions of authors expressed herein do not necessarily state or reflect those of the United States Government or any agency thereof. 


\section{DISCLAIMER}

Portions of this document may be illegible in electronic image products. Images are produced from the best available original document. 


\section{Printed in the United States of America. Available from National Technical Infümation Service \\ U.S. Department of Commerce 5285 Port Royal Road, Springfield, Virginia 22161 \\ Price: Printed Copy $\$ 5.25$; Microfiche $\$ 3.00$}

This report was prepared as an account of work sponsored by an agency of the United States Government. Neither the United States Government nor any agency thereof, nor any of their employees, contractors, subcontractors, or their employees, makes any warranty, express or implied, nor assumes any legal liability or responsibility for any third party's usp or the results of such use of any information, apparatus, product or process disclosed in this report, nor represents that its use by such third party wnuld not-infringe privately owned rights. 
ORNL/TM-6355

Contract No. W-7405-eng-26

INSTRUMENTATION AND CONTROLS DIVISION

SALTY

A HYBRID COMPUTER PROGRAM FOR THREE-DIMENSIONAL HEAT TRANSFER FROM A DISCRETE SOURCE

R. S. Stone O. W. Burke

Date Published: June 1978

NOTICE: This document contains information of preliminary nature. It is subject to revision or correction and therefore does not represent a final report.

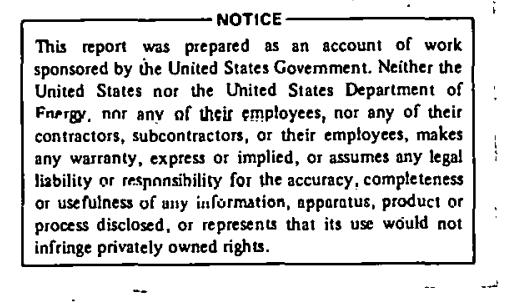

OAK RIDGE NATIONAL LABORATORY

Oak Ridge, Tennessee 37830

operated by

UNION CARBIDE CORPORATION

for the

DEPARTMENT OF ENERGY 


\section{THIS PAGE}

\section{WAS INTENTIONALLY \\ LEFT BLANK}




\begin{abstract}
SALTY, a hybrid computer code, has been written for calculation of the temperature distributions in an extended medium with spatially varying properties and one or more discrete energy sources. Such complex, multidimensiona1, time-dependent simulations constitute one useful application of the parallel computation and continuous integration capabilities of the analog-digital hybrid computer. An application of SALTY to a problem involving nuclear waste disposal in salt is described, and the results are compared to those from the pure digital code HEATING5. SALTY gives much the same results at a lower computer cost. Differences in the results are discussed.
\end{abstract}




\section{THIS PAGE}

\section{WAS INTENTIONALLY \\ LEFT BLANK}


CONTENTS

Page

1. INTRODUCTION ...................... . . . 1

2. STRUCTURE OF THE MODEL . . . . . . . . . . . . . . . . . . 1

3. DIGITAL COMPUTER CONTRIBUTION . . . . . . . . . . . . 9 9

3.1 Digital Computer Program .............. 9

4. ANALOG CIRCUITRY . . . . . . . . . . . . . . . 12

5. SAMPLE PROBLEM . . . . . . . . . . . . . . . . . . 14

REFERENCES . . . . . . . . . . . . . . . . . . . . 32

APPENDIX A . . . . . . . . . . . . . . . . . 35

APPENDIX B ........................ . . 51 


\section{THIS PAGE}

\section{WAS INTENTIONALLY \\ LEFT BLANK}




\section{vii}

FOREWORD

This report was prepared by the Instrumentation and Controls Division of the Oak Ridge National Laboratury in cooperation with the Office of Waste Isolation and is a part of the National Waste Terminal Storage Program. The principal objective of this program is to establish facilities in various deep geologic formations at several locations in the United States which will safely dispose of commercial radioactive waste. This report documents the use of a hybrid analog-digital computer to solve heat transfer problems associated with the burial of radioactive waste. As a part of the Thermal Analysis Studies of the Office of Waste Isolation, this report compares cost and results with the digital code HEATING5 . 


\section{INTRODUCTION}

Impetus for development of a hybrid heat transfer program came from the long running times required by the digital program HEATING ${ }^{1}$ when calculating transient temperature distributions surrounding buried heat sources. Interest in mine stability and environmental consequences resulting from burial of nuclear fuel cycle wastes has led to a need for detailed calculations of heat transfer in geological media. These calculations involve complex multidimensional, time-dependent equations, and typical.ly require long runs on large digital computing facilities. To determine the extent of possible savings in cost and time, the heat transfer equations were programmed on an analog-digital hybrid computer for a feasibility study. The advantage of an analog machine in such an application is that it provides fast, continuous, simultaneous solutions to a substantial number of coupled differential equations. In many instances this parallel-running capability precludes the need for iterative runs to reach convergence. By making computations simultaneously instead of in series, and by avoiding iteration, the savings in time can sometimes be enormous. Adding a close-coupled digital computer to the analog machine permits "sharing" the analog matrix so as to expand the number of equations which can be addressed. In addition, the digital advantages of memory, preprogramming, and virtually unlimited function generation are provided.

\section{STRUCTURE OF THE MODEL}

The system which SALTY is set up to handle is a rectangularcoordinate array of 20 heat-conduction nodes, taken 4 in the y-direction and 5 in the $x$. For the required level of complexity of the nodes this takes most of the available capacity of the analog machine. Figure 1 shows the analog programming. Digital programming is provided to share this $x-y$ matrix among sequential locations in the $z$ dimension. The program listing is provided in Appendix A. The nodes may be spaced as

desired with no requirement for equal increments, though it is preferable for the $x-y$ spacings to be the same at every $z$-level. Each node is a 


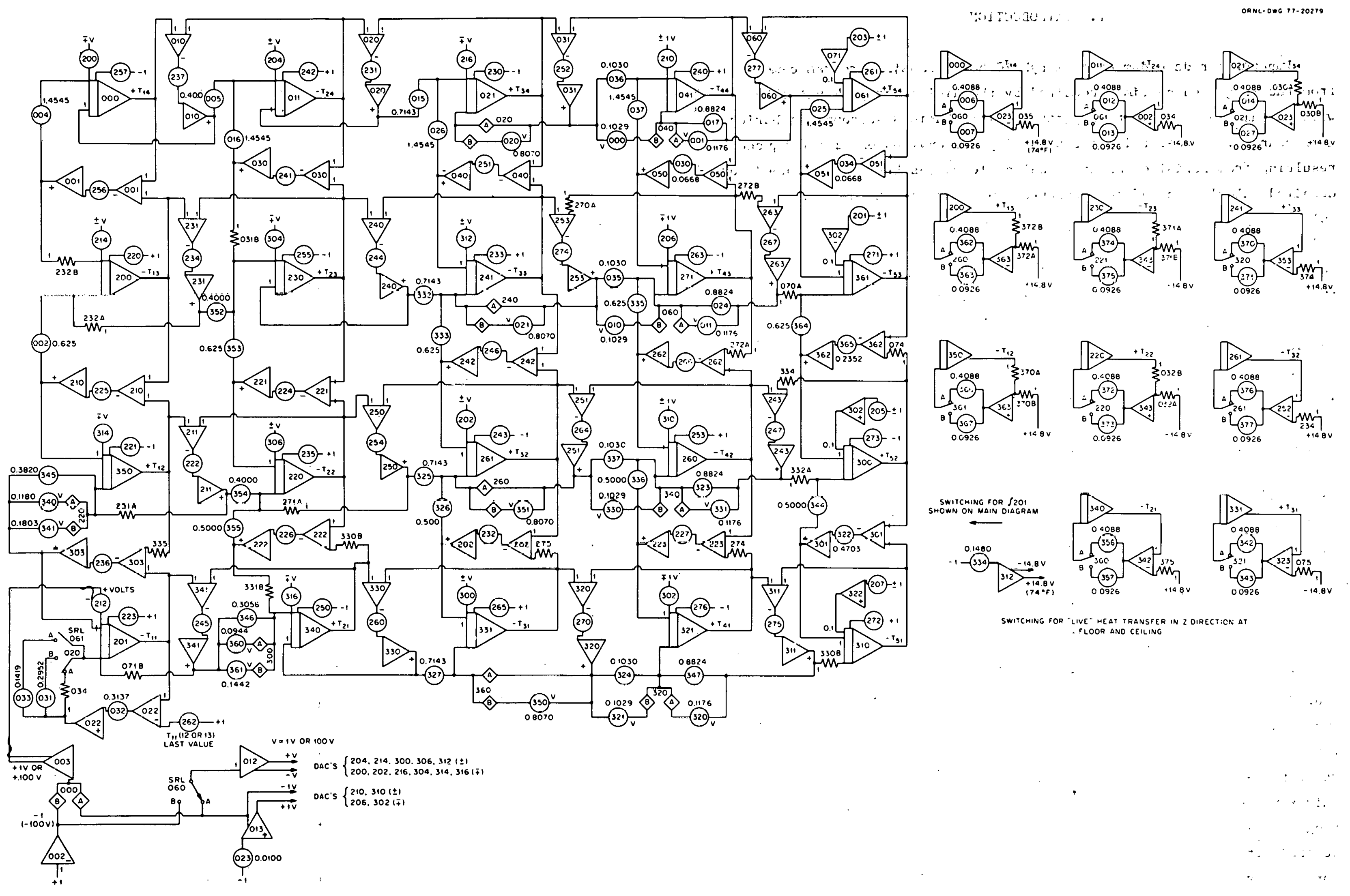

Fig. 1. Analog patching diagram. 
finite difference representation of one spatial element and contains an analog integrator to provide time integration of the net thermal input; this latter value, divided by the heat capacity, provides a continuously updated temperature reading. Table 1 lists the variables used in the analysis.

Equations used for heat flow are of the form

$$
\frac{\partial T}{\partial t}=\frac{k}{\rho c} \sum_{s}^{x, y, z} \frac{\left(T_{n-1}-T_{n}\right) s}{\Delta S_{s I} \Delta S_{s 2}}+\frac{\left(T_{n+1}-T_{n}\right)}{\Delta S_{s 1} \Delta S_{s 3}} .
$$

Because the nodes are, in general, not uniformly spaced, $\Delta \mathrm{S}_{s l}$ (the length of the node in the $s$ direction) is not always the same as $\Delta S_{s 2}$ and/or $\Delta S_{s 3}$ (forward and backward distances between nodes along $s$ ). As used in the model, $\Delta \mathrm{S}_{s 1}=0.5\left(\Delta \mathrm{S}_{s 2}+\Delta \mathrm{S}_{\mathrm{s} 3}\right)$.

Temperatures are represented by scaled voltages, and $x-y$ thermal resistance between nodes by digitally set attenuators, or "digital coefficient units" (DCUs). Settings of the DCUs may be functions of geometry, material, and temperature, and are periodically recalculated and updated by the digital computer. In the $z$ direction, since adjacent temperatures are not continuously available as analog inputs, the vertical contribution to the heat transfer integrand is held constant throughout each time step. Inasmuch as analog integration is continuous rather than stepwise incremental, the term "time step" simply signifies an interval over which the analog coefficients are held constant. For any given step the integration time must be identical for all 20 nodes in the $x-y$ array, but it may be varied for different positions in the $z$ dimension. This option permits longer time steps in those regions where larger spatial steps in $z$ are used, and where the time constants are, therefore, correspondingly greater. The length of the time step may also be varied as a function of time, for example, steps may be shorter for a freshly perturbed system, and longer as equilibrium is approached. This approach helps to minimize run time by limiting the number of digital operations to no greater a number than accuracy and stability require. A few trial runs may be needed to optimize step length as a function of time and location. 
The length of the time step is programmed by timer choices available in the logic portion of the analog machine. For example, for the sample 30-year waste isolation problem-described later in this report, the analog is scaled at a ratio of $1 \mathrm{sec}$ machine time to $1 \mathrm{yr}$ of simulated time, with time-step choices of $0.0001,0.0005,0.001,0.0025,0.01$, and $1.0 \mathrm{sec}$ $(y x)$, the value used being a function of the elapsed time since the transient began. The time step chosen is determined by digital programming, operating through reevaluations of the control word ITWD. This selection takes place early in the program, as shown on page 38 of the program listing (Appendix A). Here, IT is the sequential number of the time step. As suggested above, the time step is also a function of the $z$ position of the $x-y$ matrix. Where sections are very thin (short time constant), the time steps may be made shorter. This is done by manipulation of the command SETLI (see page 46), by which the timer pattern set in by ITWD is modified. Where sections are very thick (long time constant), the time steps may be made longer and changed less frequently, since the integrand is not changing rapidly. Rather than running 100 times longer, the same smaller time step can be used, but with an integrand 100 times the actual value. The quadratures are then pertormed only every 100th pass. In the sample problem, this means that in the blocks hundreds of feet thick, such as are used in the areas remote from the thermal perturbation, temperatures and material properties are updated only once a year, while most $z$ levels are updated every $0.01 \mathrm{yr}$, and the two thinnest sections are reevaluated every $0.001 \mathrm{yr}$. These operations are shown on page 46 , where IZ refers to the $z$ position, with the IZ value representing an ordinal listing of the $z$ nodes from the bottom up. In the sample problem there is a total of 31 IZs, with No. 1 (deep earth) and No. 31 (surface) held at fixed temperatures. Values of IZ that are $\leq 6$ and $\geq 25$ are updated only once a year.

Time steps from $1 \mu \mathrm{sec}$ to $100 \mathrm{sec}$ are available by patching on the analog logic board. There are 16 digital control lines on the analog logic panel, numbered from DGC 0 to DGC 15. In general, the function of these control lines is to alter the time step as desired, to alter geometry as required by certain $z$ levels, and to control the operating mode of the analog machine. These lines are set on or off depending on the 
Table 1. List of variables and their definitions.

\section{Thermal conductance}

Heat capacity per unit mass

Heat capacity (reciprocal)

Heat capacity for special cases (reciprocal)

Geometry factor in downward direction

Geometry factor in upward direction

Geometry factor in $x$ direction

Geometry factor in $y$ direction

Heat transfer coefficient between air and room surface

Conductivity in upward direction

Conductivity in downward direction

Name of array containing digital coefficient device addresses

Name of array containing addresses of analog amplifiers

Name of array containlng addresses of servo-get potentlomerers

setword argument used to set the bit pattern in control line register

Time step count variable

IT

Array containing node temperatures as read from analog amplifiers

ITEMPT

Part of INIT dependent on time-step count, IT

IVD Array containing digital coefficient device values or settings

IVP Array containing servo-set potentiometer values or settings

Node index in $x$ direction

Node index in $y$ direction

Node index in $z$ direction

Part of INIT dependent on $z$ level, IZ

Number of analog-to-digital converter lines used in problem

Number of amplifiers used in problem

Number of digital coefficlent devices used in problem

Number of servo-set potentiometers used in problem

Waste heat generation rate as a function of time after burial, expressed as

a fraction of the rate at time of burial

PWR Heat generated by radioactive decay

$q_{v}$ Volumetric rate of power generation

$R$ Thermal resistance

$\Delta S_{G l} \quad$ Length of node in $s$ direction

$\Delta S_{s 2}$ Center-to-center backward distance to adjoining node in $s$ direction

$\Delta S_{s 3}$ Center-to-center forward distance to adjoining node in s direction

SFT Time scale multiplier

SFX Scale factor for $x$ direction

SFY Scale factor for y direction

SFZ Scale factor for $z$ direction

T Time in years

TEMP Array containing values of node temperatures for a particular time-step

TEMPER Array containing temporary values of node temperatures for a particular time-step

TEMPRT Array containing values of node temperatures to be printed on line printer

V Volume

XHT . Time rate of change of temperature in $x$ direction

YHT Time rate of change of temperature in $y$ direction

YPLN $y$ distance expressed in feet

ZDIST $z$ distance expressed in feet

ZHT Time rate of change of temperature in $z$ direction

ZHT1 Contribution to ZHT in upward direction

ZHT2 Contribution to ZHT in downward direction

p Density 
makeup of the 5-digit hybrid call SETWD. Table 2 lists the control line numbers, together with the SETWD components which set them high. For example, a SETWD of $8200(=8192+8)$ would set DGCs 2 and 12 . In program SALTY, the call SETWD is broken into two components, IZWD and ITWD. IZWD makes $z$-level dependent changes in the control lines to implement changes in geometry or materials with depth. Involved are DGCs 2, 3, 4, 5, 8, 9, and 10 (see Figs. 1 and 2). ITWD sets the time-step control lines that depend on the time variable and involves time-step DGCs 0 , 11, 12, and 13. The initial-condition control line, DGC 15, is set at the same time. If all five of these time-step depcndent lines were set high, ITWD would be set to 32797. The analog logic diagram for the time-step is shown in Fig. 2a. An ITWD value of 29 (i.e., 32.797 - 32768) would set DGCs $11,12,13$, and 15 high and DGC 0 low, thus selecting the 100-usec timing rate. (A timing rate is selected by setting its associated DGC low; see Fig. 2.) An ITWD value of 32793 (i.e., 32797 - 4) sets all time lines high except DGC 13, thus selecting the 1-msec timing rate: The situation is more complex when ITWD $=32789$ (or $32797-8$ ) is selected, and DGC 11 goes low. In this situation the time step can be either 0.5 or $2.5 \mathrm{msec}$, depending un whethrer DGG 14 is high or low. This decision is z-dependent, and DGC 14 is set independently of SETWD by the SETLI command. Page 46 includes the applleable prugramming. Also, page 38 contains instructions which determine the ITWD structure at various time intervals after the start of the program.

In the absence of option routines in the program, the timing instructions just discussed must be edited and altered to fit the system under evaluation. The rate of change of the driving function as a function of time and the thermal time constants of the nodes as a function of $z$ will

Table 2. Control lines turned on vs digital components present In SETWD

\begin{tabular}{lrrrrrrrr}
\hline Control Line No. & 0 & 1 & 2 & 3 & 4 & 5 & 6 & 7 \\
SETWD Component & 32768 & 16384 & 8192 & 4096 & 2048 & 1024 & 512 & 256 \\
Control Line No. & 8 & 9 & 10 & 11 & 12 & 13 & 14 & 15 \\
SETWD Component & 128 & 64 & 32 & 16 & 8 & 4 & 2 & 1 \\
\hline
\end{tabular}




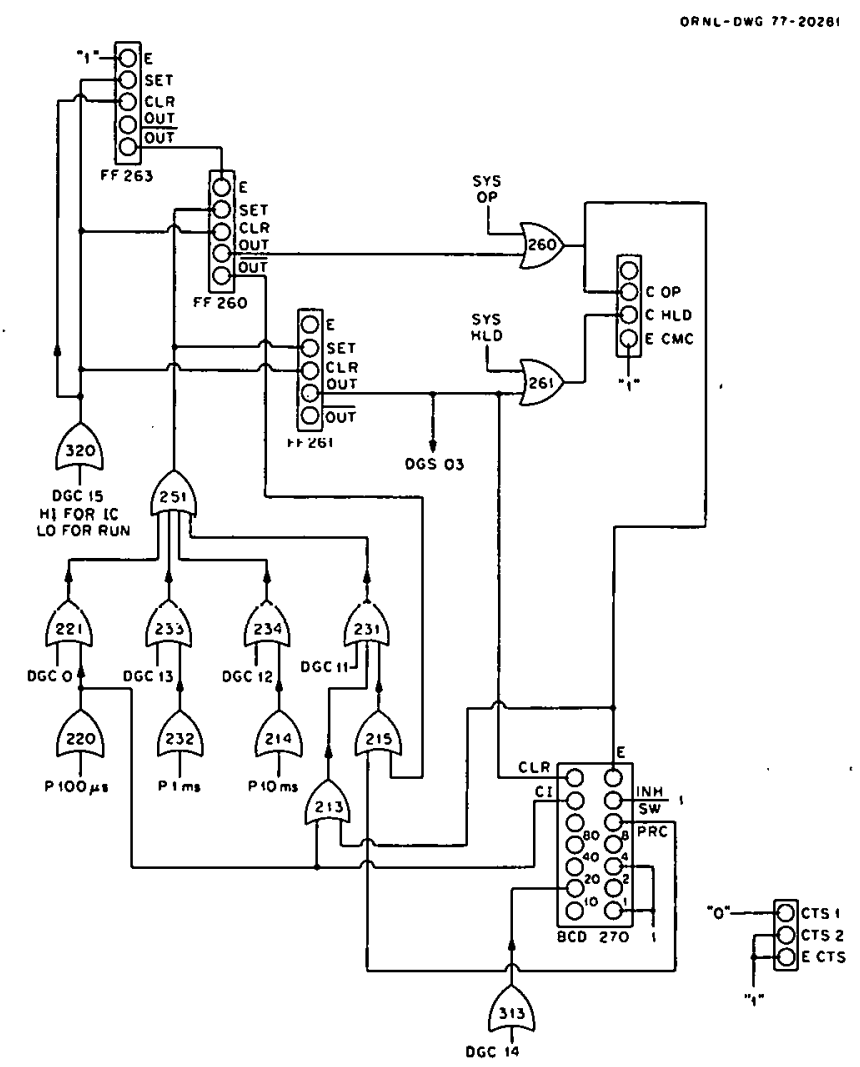

a. Patchable logic diagram for time-step contro1.

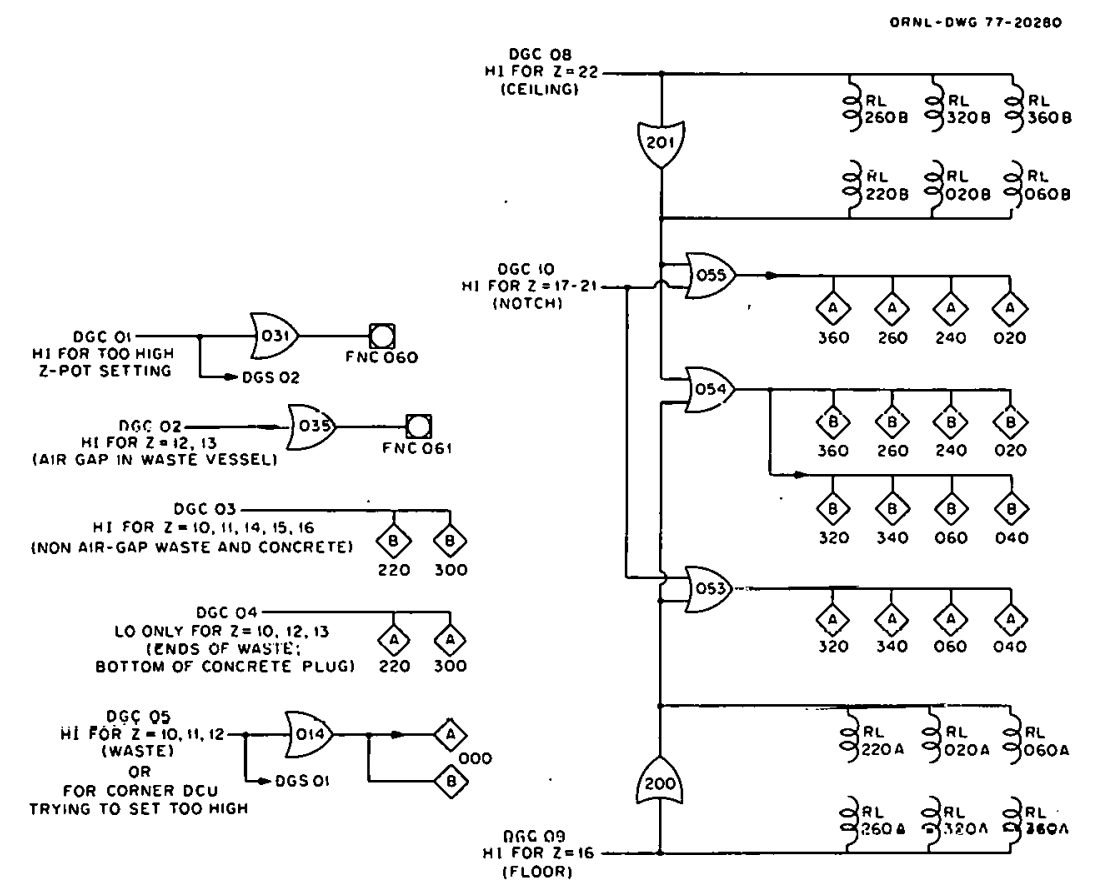

b. Patchable logic diagram for spatial variations.

Fig. 2. Configuration of patchable logic elements. 
be the determining factors in the pattern of time steps which is actually chosen. Too many steps lead to longer than necessary running time; too few steps lead to instability and "hunting" in the solution.

For the example program whose listing appears in Appendix A, time steps depend upon both IT and IZ, as shown in Table 3. Qualitatively, steps can be longer where $z$ thicknesses are greater; they must be shorter where $\mathrm{z}$ thicknesses are thin or at the start of the run where temperatures are changing most rapidly. Time-dependent relations are called out by ITWD determinations on page 38; $z$-dependent exceptions to these are determined by SETLI calls introduced on page 46. As an example, the call SETLI ( $0,0,11, U)$ indicates that DGC 11 is lu le set low, regardlaes of the value of the corresponding ITWD.

To summarize, the control lines are addressed en masse by SETWD, of which ITWD is a component, or individually by SETLI. For $z$ levels 7-11 and 22-24, there are 514 time steps in the first year's simulation. From that point on, there are $1,100,400$, or 1000 steps per year, depending on the $z$ level. Because of their low heat capacity and steep thermal gradient, levels 15 and 16 have more time steps. To further smooth the behavior at the $z=16$ level (burial chamber floor), the vertical heat transfer value at that level is made equal to the average of the value most recently calculated and the value from the preceding time step. At this same $z$-level, the equations for convection to air in the roum or conduction to salt in the pillar are differentiated by variations in analog programming on an $\mathrm{x}$-dependent basis. Logic programming is shown in Fig. 2b.

Table 3. Length of time step ( $y r$ ) as function of vertical position and elapsed time

\begin{tabular}{lcccc}
\hline $\begin{array}{c}\text { IT Value } \\
\text { (No. of } \\
\text { time step) }\end{array}$ & \multicolumn{4}{c}{ IZ position } \\
\cline { 2 - 5 } & $1-6,25-30$ & $7-11,22-24$ & $12-14,17-21$ & 15,16 \\
\hline $0-100$ & 1 & 0.0001 & 0.0001 & 0.0001 \\
$101-130$ & 1 & 0.001 & 0.001 & 0.0005 \\
$131-514$ & 1 & 0.0025 & 0.0025 & 0.0005 \\
$515-3414$ & 1 & 0.01 & 0.0025 & 0.001 \\
\hline
\end{tabular}


On page 39 the elapsed time in years $\mathrm{T}$ is determined in terms of the current time-step IT in a number of program algorithms, and the relative source strength PFR is determined as a function of $T$. On page 40 (reciprocal) heat capacity $\mathrm{CP}$ and the temperature-dependent heat transfer coefficients HKI and HK2 are selected.as functions of spatial position. These variables are problem dependent.

\section{DIGITAL COMPUTER CONTRIBUTION}

The digital computer portion of the hybrid computer system is assigned the following tasks:

1. Calculate the values to be used to set the analog coefficient devices [coefficients in Eq. (1)].

2. Direct the setting of the analog coefficient devices.

3. Control the operation of the analog computer through the patchable logic elements on the analog console.

4. Read the outputs from the analog amplifiers, store the values, and print them out at the conclusion of the run.

The FORTRAN IV language is used to program the DEC PDP-10 digital computer. FORTRAN callable hybrid computation routines (HCRs) are used to communicate with the analog computer.

\subsection{Dig1tal Computer Program}

A flow diagram of the digital computer program is shown in Fig. 3, and a listing of the digital program is shown in Appendix A.

The digital program is largely composed of a collection of nested DO loops. The outermost loop, containing the tasks to be done during a particular time step, is the time-step loop having the index "IT." The next loop inside the time-step loop performs the tasks associated with each $z$ level; its index is "IZ." Three loops inside the $z$-1evel loop calculate the coefficients for the transient heat conduction equation, Eq. (1), at each of the $20 \mathrm{x}-\mathrm{y}$. locations.

To begin the program, the initial values for the variables and the values of the constants used in the problem are read into the digital 
computer. Under digital program control the analog computer is interrogated to ensure that all the equipment to be used is operational. The analog computer is placed in the initial condition mode, and the constantvalue servo-set potentiometers are set.

The time-step loop is then entered. The program chooses the timestep size for the particular time-step or IT value by setting the arguments in the SETWD call to such a value as to activate the proper logic control lines on the analog machine. The effectlve time step size varies from $100 \mu \mathrm{sec}$ to $1 \mathrm{sec}$ at a scale of $1 \mathrm{sec}=1 \mathrm{yr}$. The steps are shorter during the rapid temperature changes at the start of the run, and lengthen as equilibrium is approached. The very long time sleps (1 yr) are used only for the massive blocks far above and below the source level. The accumulated time in years is continually totaled, and at each time step the appropriately decayed power generation rate is set in as a source factor. The source is constant during each time step. The program next enters the $z$-level loop, where the logic control line pattern is set to that appropriate for the current $z$ level. The analog computer is placed in the initial condition mode.

The loop for calculating the cutflicienta for heat transfer in the $z$ direction is entered next. Most of the heat transfer coefficients are temperature dependent, and, because of changes in matcrial, they are. position dependent as well. Since z-direction $\Delta \mathrm{T}^{\prime} \mathrm{s}$ are fixed during each time step, the $\Delta T^{\prime} s$ are included in the $z$-direction heat transfer coefficients. The heat transfer loop makes 20 calculations, one for each of the nodes in the $x-y$ plane.

Loops for calculating the coefficlents for heat transfers in the $x$ and $y$ directions are also made part of the $z$-level loop. These loops are similar to the loop for the z-direction calculations, except that $\Delta T^{\prime} \mathrm{s}$ in the $\mathrm{x}$ and $\mathrm{y}$ directions are continuously calculated on the analog machine; they are not constant values from the previous time step as are the driving functions in the $z$ direction. The analog computer is put in the OPERATE mode by a command from the digital computer. The patchable logic on the analog computer places the analog in the HOLD mode at the end of the time-step interval, as determined by a digital clock in the analog machine. The digital computer interrogates the analog logic until 


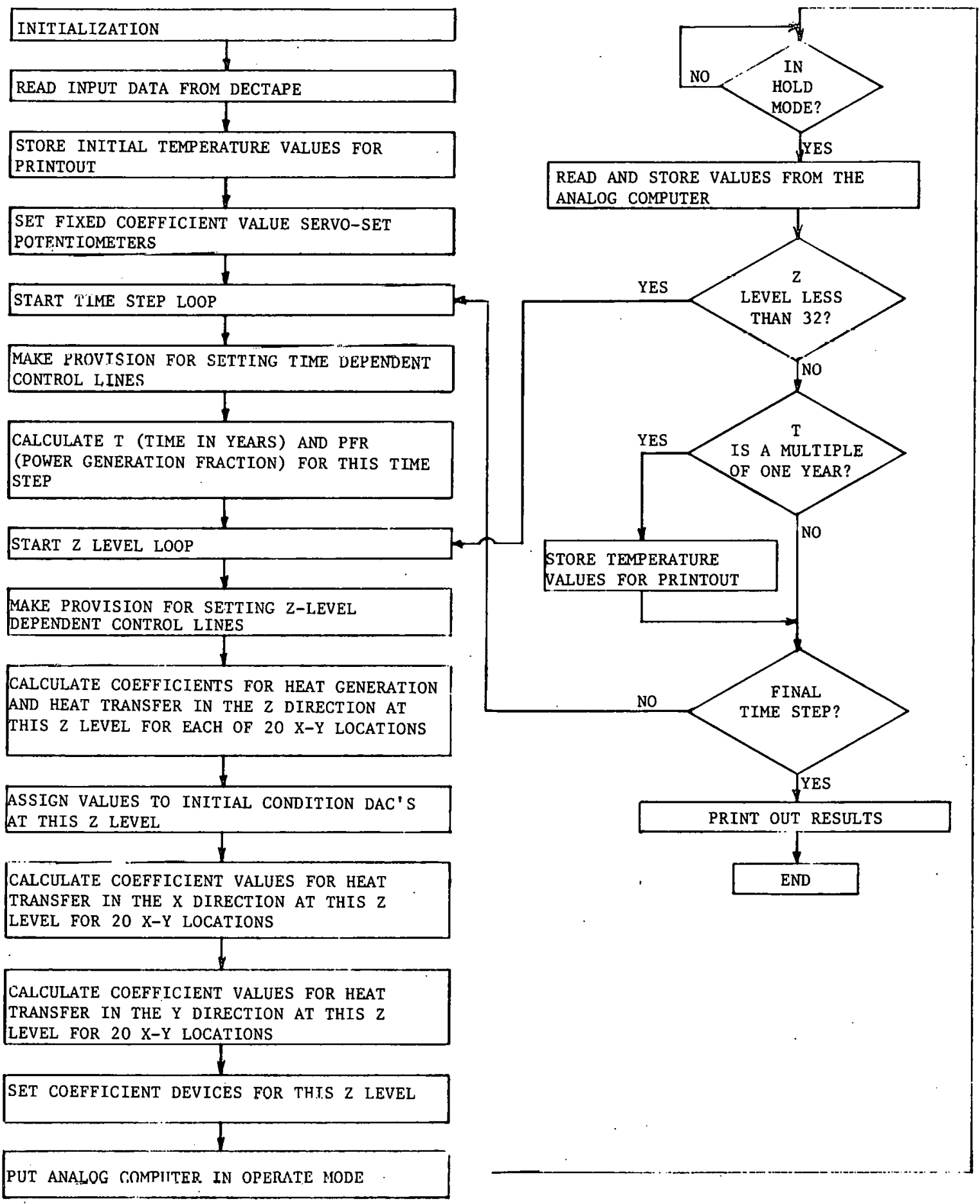

Fig. 3. Digital rnmputer program fluw dlagram. 
it is informed that the analog is in the HOLD mode, at which time it reads the output values of the 20 integrators (temperature generators) and stores the values. This completes the $z$-level loop; the process is repeated a $z$-dependent number of times at each $z$ level for every repetition of the time-step loop. For the large z-steps at each end of the vertical range, integration may come as infrequently as once every hundred time steps. The temperature values are stored at 1 -yr intervals for final printout. This completes the time-step loop:

The loop is repeated for a sufficient number of time steps to make up the scaled-problem time. At the conclusion of the last time-step loop, the temperature values that have been stored at 1-yr intervals are printed out on the line printer. This concludes the program.

\section{ANALOG CIRCUITRY}

The analog circuit used is shown in Fig. 1, with the controlling logic patching in Fig. 2. The $4 \times 5$ matrix of analog integrators represents the $4 \times 5$ matrix of temperature nodes described. in Sect. 2 . Each integrator with lls dssoclulud summrn nnd attenuators solves Eq. (1) at one specific node in the system under study. Nodes are closely spaced near sources, but are more wldely spided uu their dir:tance from the source increases. Difference amplifiers generate the $\Delta \mathrm{T}$ between adjacent cells, and digitally set coefficients multiply this $\Delta \mathrm{T}$ by the appropriate heat transfer, heat capacity, and geometric coefficients. The maximum analog voltage $(150 \mathrm{~V})$ is scaled to the maximum cxpected temperature. In the test case this was the maximum initial temperature in the waste.

In the $x-y$ plane all temperatures are continuously updated, with all 20 in equilibrium with each other at all times. For heat. flow in the z-direction, the $\Delta T^{\prime} s$ are not continuously updated, and the values applied during each time step are those measured at the end of the preceding interval, just as would be done for all $\Delta \mathrm{T}^{\prime} \mathrm{s}$ in an all-digital code. Similarly, the material properties are, in general, temperaturedependent, but are held constant during each time interval and updated at the end of each time step at the same time as the $\Delta \mathrm{Tz}$ 's. During the 
reading and updating process, the analog machine is switched to the HOLD mode.

The $\Delta T^{\prime}$ s between each individual station and the stations immediately above and below it are fixed during each time step, and are set to the values read at the end of the preceding time step, as stored in the digital memory. Exceptions are made at all air houndaries, where stability considerations make it desirable for $\Delta \mathrm{T}$ to. vary during the time step. Computations start at the level of the source centerline and move upward; the $x-y$ matrix is integrated at successive $z$-levels until the upward extreme -- a constant temperature boundary condition -is reached. Having finished all levels from the source centerline to the upward extreme, the program begins again immediately below the source centerline, starting with the centerline at the temperature achieved at the end of the immediately preceding run. This centerline offset in time is necessary so that the central temperature may be reduced by the heat lost in both directions. Starting just below the source centerline, integrations are run for one time step at progressively lower levels. At the lower extreme, as at the upper extreme, there is a constant temperature boundary condition. Completion of the lower leg completes one time step, and the matrix is reprogrammed to start again at the midsource level.

In Fig. 1 auxiliary switching is shown applied to the integrators in various areas of the diagram. This switching has the general function of altering conduction paths between $x-y$ nodes when the $z-1$ evel reaches a void or other discontinuity. Dlglial-analog converters (DACs) supply those inputs which remain constant during each time step. These fixed DACs have a choice of 1 - or $100-V$ inputs, depending on the level of the fixed input desired $(100 \mathrm{~V}$ for an included source or for a high vertical gradient; $1 \mathrm{~V}$ for a small vertical gradient). This choice of inputs ellsures that the DAC need not be set too low for accuracy when settings are small, or that the DAC will not overrun its range when settings are large. The choice is made following computation of the desired coefficient in the digital cumputer. 


\section{SAMPLE PROBLEM}

The hybrid program SALTY was applied to calculation of a nuclear waste burial problem previously run using the digital program HEATING5 so that we could compare the hybrid and digital numerical results and running times.

The model to be described simulates one unit cell in a hypothetical, but typically configured, waste repository in bedded salt. The room and pillar excavation is assumed to lie $2000 \mathrm{ft}$ below the surface, where an infinite array of infinitely long, 18-ft-square rooms are separated along their axes by pillars $60 \mathrm{ft}$ thick. Waste canisters $2 \times 2 \mathrm{ft}$ in cross section and $8 \mathrm{ft}$ long are assumed buried in a vertical position every $17 \mathrm{ft}$ down the centerline of each room. The tops of the canisters lie $10 \mathrm{ft}$ below the floor of the room. Immediately above each canister is a 3-ft airspace, and this is overlain by a 7-ft concrete plug. Figure 4 shows the assumed geometry in the vicinity of the repository room.

The unit cell is a rectangular prism with one vertical edge, the z-axis, running through the centerline of a waste canister and extending from the surface of the earth (2000 ft above the repository floor) to a point $4000 \mathrm{ft}$ down (2000 ft below the repository floor). Figure 4 shows the configuration. 'l'he origin of coordinates is at the level of the repository floor. The $y$-axis runs along the centerline of the floor; in this direction the unit cell extends from the axis of the waste canister to the line of symmetry halfway to the next burial hole, a distance of $8.4 \mathrm{ft}$. The $\mathrm{x}$-axis is perpendicular to the other two axes; the unit cell extends in this direction from the axis of the waste canister to the centerline of the bounding pillar, a distance of $39 \mathrm{ft}$. This division slices the waste canister Into four longitudinal sections, one of which lies in the unit cell which is simulated.

A change from pure salt (below) to a mixture of salt and shale (above) is assumed to take place at the level of the repository ceiling. Coolant air under forced convection is assumed to flow through the repository, keeping the air temperature in the room at a constant $74^{\circ} \mathrm{F}$. 


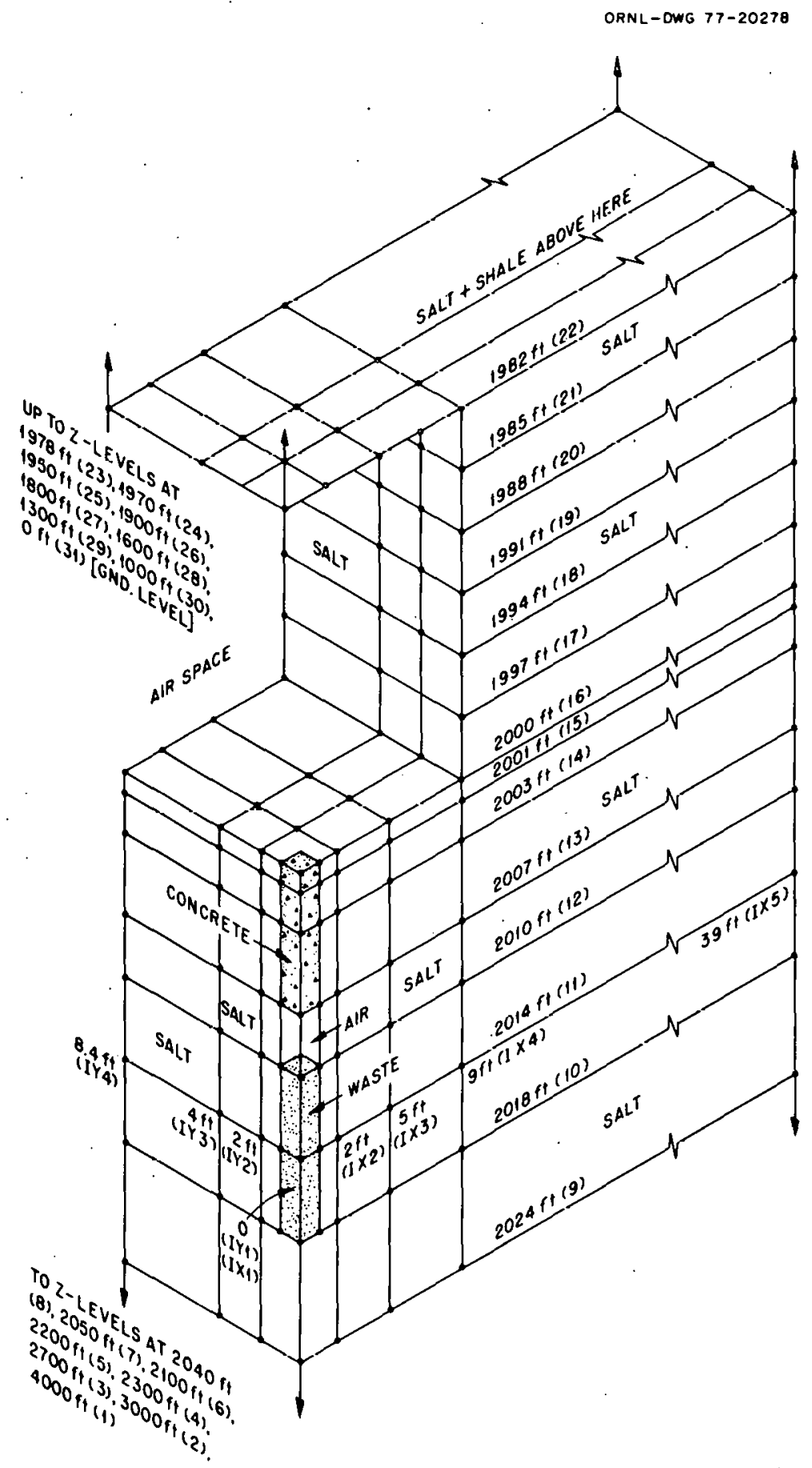

Fig. 4. Repository plan (unit cel1). 
The $x-y$ matrix described in Sect. 2 is applied to this geometry, with nodes centered at $0,2,5,9$, and $39 \mathrm{ft}$ in the $x$-direction, and at $0,2,4$, and $8.4 \mathrm{ft}$ in the y-direction. Stations in the $z$-direction are selected under program control from the digital computer; there are 29 active stations as well as 2 constant-temperature boundary condition stations at the upper and lower extremes. The model grid is shown in Fig. 4, where the vertical levels chosen are identified. The digital program identifies the grid points by numerical designation of the vertical position, as shown in parentheses in Fig. 4, for example, the repository floor is at "Level $16 . "$

There is a steep temperature gradient in the area of the room floor. This is the 2000-ft level, or in the nomenclature of the program, "Level 16." To aid stability, the time steps at Levels 15 and 16 are of shorter duration than those allotted to the adjacent $z$-levels. Moreover, in calculating the vertical $\Delta \mathrm{T}$ applied to Level 16, an average of the last two time steps is taken to avoid the temperature "see-sawing" which can develop between time steps in this sensitive area. In addition, exceptions to the program of fixed $\Delta T^{\prime} s$ in the $z$-direction are provided at the floor and ceiling of the burial roum. Since the comperaluie gradient at these locations makes fixed $\Delta T^{\prime}$ s conducive to instability, and since the air temperature is constant and known, it is relatively easy to introduce the same continuous updating of $\Delta T$ in the $z$-direction as is done for $x$ and $y$.

Continuously variable $\Delta \mathrm{T}$ is also provided across the air gap above the canister of waste, where radiative heat transfer occurs from the top of the waste to the bottom of the concrete plug. If this waste-tuconcrete radiation is included in the simulation, the relatively large $\Delta \mathrm{T}$ makes this area a particularly troublesome spot in regard to calculational instability. To avoid this, the hybrid model uses "half-continuous, half-stepwise" $\Delta \mathrm{T}$ formulation at the air gap. When the rate of change of the temperature at the bottom face of the concrete plug is calculated, the program uses as the radiative $\Delta \mathrm{T}$ the difference between the instantaneous concrete temperature and a constant set to the last known temperature at the top of the waste. Conversely, when the temperature rate of change at the top level of the waste is calculated, the radiative 
$\Delta \mathrm{T}$ is formed between the instantaneous waste temperature and a constant set to the last known temperature at the bottom of the concrete. This arrangement permits the driving $\Delta \mathrm{T}$ to instantaneously go down as heat transfer goes up, with no wait for the end of the time step. The resulting negative feedback stabilizes the computation by avoiding temperature overshoot.

A diagram of the waste-concrete air gap is shown in Fig. 5. The view factor from node to node (end to end) is only $3 \%$. An argument can be made, however, for including part of the walls of the cavity in the view factor. In brief, for the hybrid model thermal radiation (solid arrows) incilent on the sides of the cavity above the halfway mark is assumed to "belong" to the concrete plug and to transfer its energy to node 13. Radiation incident on the walls below the halfway mark (dotted arrows) is assumed to be a "failed escape" and is ignored in the heat transfer. The net geometry factor is $3 \%$ for the end of the cavity (bottom of the concrete) and $2.2 \%$ for the top ends of each of the four sides, for a total of $11.8 \% .^{2}$

Radiative heat transfer is governed by the formula

$$
\dot{\mathrm{H}}=\sigma \varepsilon \mathrm{FA}\left(\mathrm{T}_{1}^{4}-\mathrm{T}_{2}^{4}\right) \text {, }
$$

where

$\dot{\mathrm{H}}=$ heat transfer from surface 1 to surface 2 ,

$\sigma=$ Stefan-Boltzmann constant $=1.713 \times 10^{-9}$ Btu ft $\mathrm{ft}^{-2} \mathrm{hr}^{-1}{ }^{\circ} \mathrm{R}^{-4}$,

$\varepsilon=$ cmissivily,

$F=$ geometry factor, that is, the fraction of radiation from one surface which is intercepted by the other,

$A=$ area of the emitting surface.

In the present example, $\varepsilon=0.90, F=0.118$, and $A=1 \mathrm{ft}^{2}$; therefore, $\dot{\mathrm{H}}=1.819 \times 10^{-10}\left(\mathrm{~T}_{1.2}^{4}-\mathrm{T}_{13}^{4}\right) \mathrm{Btu} / \mathrm{hr}$. Since rates of change are low in the simulation, this equation is rescaled to

$$
\dot{\mathrm{H}}=1.594 \times 10^{-6}\left(\mathrm{~T}_{12}^{4}-\mathrm{T}_{13}^{4}\right) \mathrm{Btu} / \mathrm{yr} .
$$


Because $T_{12}^{4}-T_{13}^{4}$ is to be a continuous function of the analog, there is an apparent need to generate two widely varying analog voltages with consequent scaling problems. This situation is resolved by factoring the temperature term:

$$
\mathrm{T}_{12}^{4}-\mathrm{T}_{13}^{4}=\left(\mathrm{T}_{12}-\mathrm{T}_{13}\right)\left(\mathrm{T}_{12}+\mathrm{T}_{13}\right)\left(\mathrm{T}_{12}^{2}+\mathrm{T}_{13}^{2}\right)
$$

In this case, $\mathrm{T}_{12}$ (the top-of-the-waste temperature) decreases as $\mathrm{T}_{13}$ (the bottom-of-the-concrete temperature) increases. Results of preliminary simulations show that the loss in one temperature is about equal to tho gain in the other; consequently, $\left(\mathrm{T}_{12}+\mathrm{T}_{13}\right)$ is almost constant, and even the cubic expression $\mathrm{K}_{\mathrm{T}} \equiv\left(\mathrm{T}_{12}+\mathrm{T}_{13}\right)\left(\mathrm{T}_{12}^{2}+\mathrm{T}_{13}^{2}\right)$ changes by only about $25 \%$ over the whole run. The hybrid formulation takes advantage of this, setting $\mathrm{K}_{\mathrm{T}}$ constant at an average value of $2 \times 10^{9}{ }^{\circ} \mathrm{R}^{3}$, thus simplifying the radiation equation to

$$
\dot{\mathrm{H}} \simeq 3187\left(\mathrm{~T}_{12}-\mathrm{T}_{13}\right) \mathrm{Btu} / \mathrm{yr} .
$$

To convert this to a rate of change of temperature, the equation is divided by heat capacity. The volumetric hual lajality po of the wnste material is taken to be $37 \mathrm{Btu}{ }^{\circ} \mathrm{F}^{-1} \mathrm{ft}^{-3}$. Since node 12 contains $2 \mathrm{ft}^{3}$ of waste, its total heat capacity is $74 \mathrm{Btu} /{ }^{\circ} \mathrm{F}$, and the uude 12 equation for temperature change due to radiation is

$$
\dot{\mathrm{r}}_{12 \mathrm{R}}=-43.07\left(\mathrm{~T}_{12}-\mathrm{T}_{13}\right){ }^{\circ} \mathrm{F} / \mathrm{yr} \text {. }
$$

The heat capacity of concrete is taken to be $35.2^{:} \mathrm{Btu}{ }^{\circ} \mathrm{F}^{-1} \mathrm{ft}^{-3}$. Since node 13 contains $2 \mathrm{ft}^{3}$ of concrete, its total heat capacity is 70.4 $\mathrm{Btu} /{ }^{\circ} \mathrm{F}$, and the node 13 equation for temperature change due to radiation is

$$
\dot{\mathrm{T}}_{13 \mathrm{R}}=+45.29\left(\mathrm{~T}_{12}-\mathrm{T}_{13}\right){ }^{\circ} \mathrm{F} / \mathrm{yr} .
$$


ORNL-DWG 77-20277

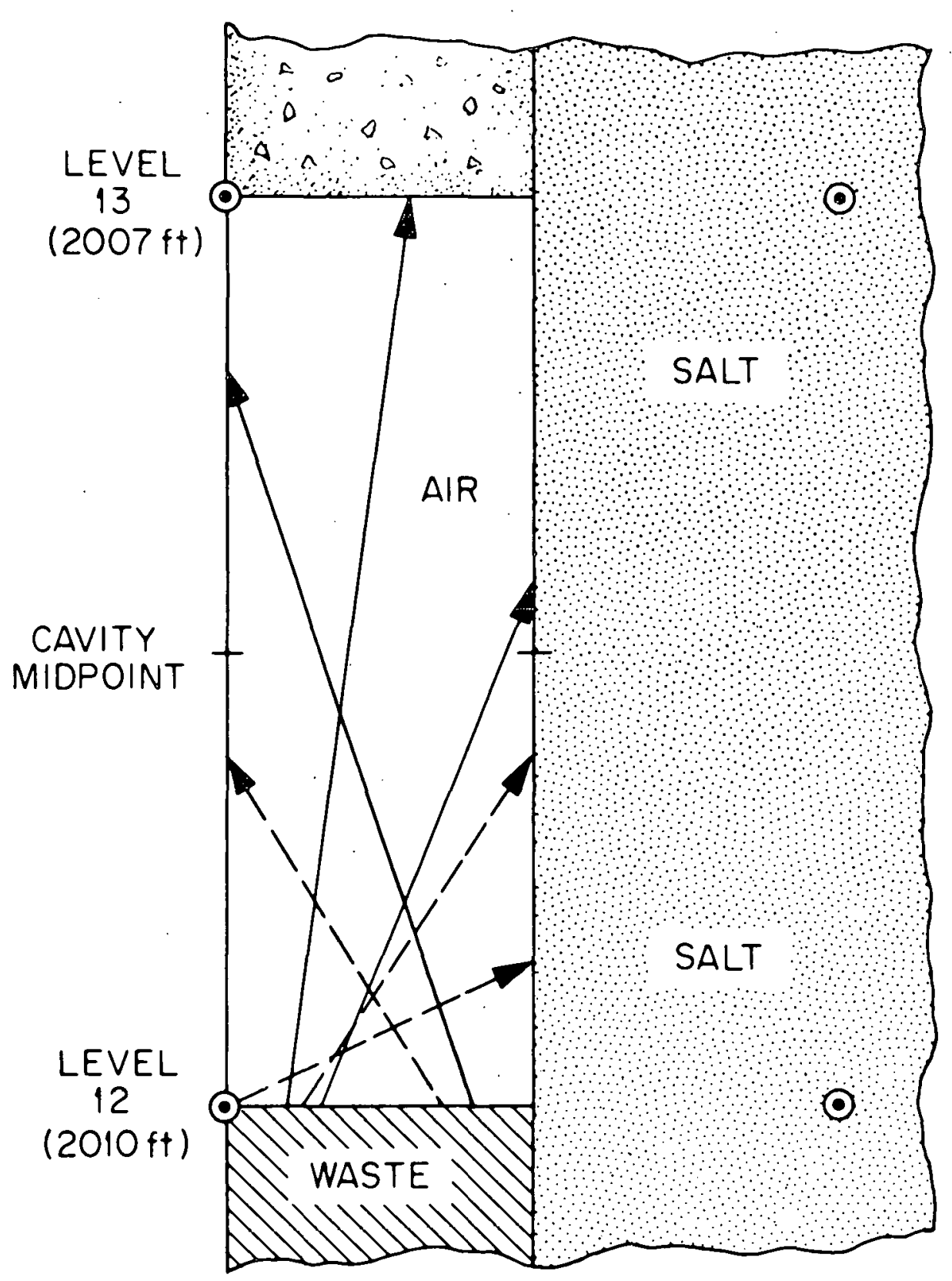

Fig. 5. Thermal radiatiuin frum waste co concrete plug. 
Numerically, the coefficients for both $\dot{\mathrm{T}}_{12 \mathrm{R}}$ and $\dot{\mathrm{T}}_{13 \mathrm{R}}$ are about the same; so, for convenience, a mean value of 44.18 is used for both. The gain of all integrators is programmed to be 1000; therefore, the potentiometer setting must be 0.0442 . With reference to Fig. 1 , the lower left-hand corner, the coefficients are 032 and 033. Inasmuch as potentiometer 032 must be set to 0.3137 as an input to switch $200 \mathrm{~A}$ at level 16 , potentiometer 033 is set to $0.0442 / 0.3137=0.1409$, and is chosen by switch $020 \mathrm{~A}$ when the computation reaches levels 12 or 13 in the corner cell and DGC 02 is actuated by the value 8192 included in IZWD. Similar paths can be traced for other changes in geometry or materials of heat transfer.

A model assuming zero heat transfer across the waste-to-concrete gap has also been implemented and run on the hybrid computer for additional insight into the sensitivity of the final temperatures to the model.

In the nodes representing waste, the right side of Eq. (1) is augmented by a heat generation term.

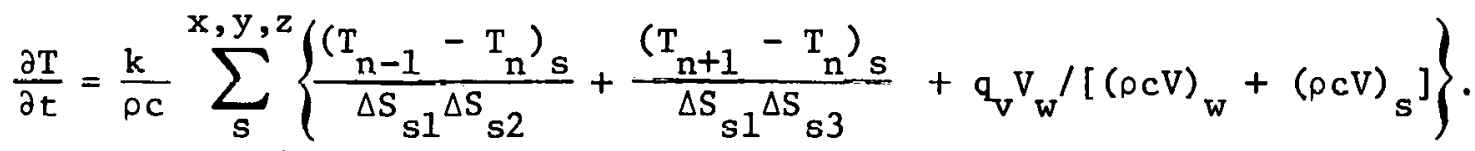

Here $q_{v}$ is the time-dependent volumetric rate of power generation, $v_{w}$ is the volume of waste, and $V_{s}$ the volume of salt associated with the node. (A node at a waste-salt interface may consist of part salt and part waste.)

In addition to the heat from the waste, there is a geothermal heat flux, as demonstrated by natural temperature rise in the earth as a function of depth. The geothermal heat flux is included in the calculations by applying a constant-temperature boundary condition of $130^{\circ} \mathrm{F}$ at the 4000-ft level. As part of the boundary condition, the model assumes a constant heat transfer coefficient of $12,830 \mathrm{Btu} \mathrm{yr}^{-1} \mathrm{ft}^{-1}{ }^{\circ} \mathrm{F}^{-1}$ for the material lying between the 3000- and 4000-ft levels. Although realistic for some geological materials, this is about half the value for pure salt at the local temperature, and is set at the lower value to force an initial temperature spread close to that used in the comparison run from 
HEATING5. The initial temperature at $3000 \mathrm{ft}$ is $105^{\circ} \mathrm{F}$, which taken with the 4000-ft boundary conditions yields an initial upward heat flux of $320 \mathrm{Btu} \mathrm{yr}^{-1} \mathrm{ft}^{-2}$. (This higher than average geothermal value is credible because the thermal conductivity of salt is higher than that of earth and rock.) Should heat from above raise the 3000-ft temperature above $105^{\circ} \mathrm{F}$, the geothermal flux will be reduced, as it would in the earth itself. A similar stratagem is used at the upper end of the vertical range. The hybrid model maintains the surface temperature at a fixed (infinite heat capacity) value of $60^{\circ} \mathrm{F}$. The next nodes down (at a depth of $1000 \mathrm{ft}$ ) will start at initial temperatures equal to their undisturbed equilibrium values, that is, $60^{\circ} \mathrm{F}$ plus the $\Delta \mathrm{T}$ to be expected from 320 Btu $\mathrm{yr}^{-1} \mathrm{ft}^{-2}$ across $1000 \mathrm{ft}$ of mixed salt and shale, or at about $76.4^{\circ} \mathrm{F}$. Should the $1000-\mathrm{ft}$ temperature rise above $76.4^{\circ} \mathrm{F}$, the heat flux to the surface will rise above the natural geothermal value. If it be desired to calculate conservative values of surface temperature changes, the surface temperature can be allowed to float, with a provision for convective heat transfer to the fixed temperature ground-level air. Inasmuch as there is only a $2.6^{\circ} \mathrm{F}$ temperature rise at the $1000-\mathrm{ft}$ level in $30 \mathrm{yr}$, it is questionable whether a change in surface temperature would be measurable.

The model described above was considered the most credible representation of the conditions assumed, and was used for most of the results to be reported. In some minor respects this model does differ from the assumptions of the HEATING5 model used for digital comparison; so for the sake of equal inputs to the compared programs, the hybrid machine was also run using the HEATING5 assumptions. One difference is in the initial conditions shown in Table 4. The right-hand set is that used in the digital run, and its origin is unknown; it was probably taken from published data for change of temperature with depth in the earth. It exhibits a constant thermal gradient of $0.021^{\circ} \mathrm{F} / \mathrm{ft}$ from top to bottom, showing no change in conductivity with temperature and no break in slope at the salt-to-salt-plus-shale interface. The left-hand set of initial conditions is that used for the standard hybrid model; it was chosen to have about the same temperature as the digital version at the repository floor, but above and below that level, it recognizes conductivity changes 
due to temperature and material differences. Because of the low heat flux, differences between the two sets are not large. Another difference is in the radiative heat transfer from the top of the waste to the bottom of the concrete plug. As discussed in connection with Fig. 5, the standard hybrid model has a geometry factor of $11.8 \%$ for this heat transfer; the available HEATING5 results assumed a factor of zero. (Initial temperatures are assumed to be same.) The differences in results are small, mainly affecting concrete temperature, and will be discussed in Sect. 6. In addition, neither of the hybrid models included thermal radiation from the repository floor, this having been assumed to be of negliglble effect. In actuality, the radiation term does beculle siginifi cant and should be included, as discussed in sect. 6 .

In the model used, the cylinder of waste is transformed into a parallelepiped to accommodate the rectangular coordinates used in the computation. Dimensions of the 10.5-in. radius, quarter cylinder in the unit cell are taken to be $1-\times 1-\times 8$-ft long. This model absorbs all of the shielding and structural material into the waste itself. The initial power output of each whole cylinder is $5 \mathrm{~kW}$, one-fourth of which is channeled into the simulated quarter-unit cell. To match the high level waste conditions in the HEATING5 comparison run, the initial power density is made $533 \mathrm{Btu}$ hr ${ }^{1} \mathrm{tt}^{3}=4.676 \times 10^{\mathrm{h}} \mathrm{Btu}^{-1} \mathrm{yr}^{-1}$, which is equivalent to $1.25 \mathrm{~kW}$ over the $8-\mathrm{ft}^{3}$ of buried waste. This decays to $1 \mathrm{~kW}$ after $7 \mathrm{yr}$, and to $0.563 \mathrm{~kW}$ after $30 \mathrm{yr}$. Decay with time is approximated by Eq. (3); where PFR is the coefficient by which initial power is multiplied, and $t$ is time after burial in years. The actual decay curve is a sum of exponentials, but over the 30-yr simulation Eq. (3) is within $1.2 \%$ of the tabulated values used in the reference digital calculation. Obviousiy, Eq. (3) can be altered to reflect the constants of processed vs unprocessed waste or to account for varying decay times before burial. The objective here is not to provide input for making waste isolation decisions but to illustrate the applicability of a hybrid computer to this type of computation. Equation (3) is as follows: 
Table 4. Temperatures $\left({ }^{\circ} \mathrm{F}\right)$ at time zero, taken at the y=zero plane through the waste sample ${ }^{a}$

\begin{tabular}{|c|c|c|c|c|c|c|c|c|c|c|c|}
\hline \multirow{2}{*}{$\begin{array}{l}\text { Elev } \\
\text { (feet } \\
\text { below } \\
\text { grade) }\end{array}$} & \multicolumn{5}{|c|}{$\begin{array}{c}\text { From Hybrid Model } \\
\text { x distance }(f t)\end{array}$} & \multicolumn{6}{|c|}{$\begin{array}{l}\text { From Digital Model } \\
\mathbf{x} \text { distance }(\mathrm{ft})\end{array}$} \\
\hline & 0.0 & 2.0 & 5.0 & 9.0 & 39.0 & 0.0 & 0.8 & 2.0 & 5.0 & 9.0 & 34.0 \\
\hline 1000 & 76 & 76 & 76 & 76 & 76 & 73 & 73 & 73 & 73 & 73 & 73 \\
\hline 1978 & 93 & 93 & 93 & 93 & 93 & 92 & 92 & 92 & 92 & 92 & 92 \\
\hline 1982 & 93 & 93 & 93 & 93 & 93 & 93 & 93 & 93 & 93 & 93 & 93 \\
\hline 1985 & .74 & 74 & 74 & 93 & 93 & 74 & 74 & 74 & 74 & 93 & 93 \\
\hline 1988 & 74 & .74 & 74 & 93 & 93 & 74 & 74 & 74 & 74 & 93 & 93 \\
\hline 1991 & 74 & 74 & 74 & 93 & 93 & 74 & 74 & 74 & 74 & 93 & 93 \\
\hline 1994 & 74 & 74 & 74 & 93 & 93 & 74 & 74 & 74 & 74 & 93 & 93 \\
\hline 1997 & 74 & 74 & 74 & 93 & 93 & 74 & 74 & 74 & 74 & 93 & 93 \\
\hline 2000 & 98 & 93 & 93 & 93 & 93 & 100 & 99 & 93 & 93 & 93 & 93 \\
\hline 2001 & 98 & 93 & 93 & 93 & 93 & 100 & 99 & 93 & 93 & 93 & 93 \\
\hline 2003 & 98 & 93 & 93 & 93 & 93 & 100 & 99 & 93 & 93 & 93 & 93 \\
\hline 2007 & 98 & 93 & 93 & 93 & 93 & 100 & 98 & 93 & 93 & 93 & 93 \\
\hline 2010 & 518 & 93 & 93 & 93 & 93 & 697 & 534 & 93 & 93 & 93 & 93 \\
\hline 2014 & 560 & 93 & 93 & 93. & 93 & 700 & 594 & 93 & 93 & 93 & 93 \\
\hline 2018 & 310 & 93 & 93 & 93 & 93 & 383 & 325 & 93 & 93 & 93 & 93 \\
\hline 2024 & 93 & 93 & 93 & 93 & 93 & 93 & 93 & 93 & 93. & 93 & 93 \\
\hline 2040 & 93 & 93 & 93 & 93 & 93 & 94 & 94 & 94 & 94 & 94 & 94 \\
\hline 3000 & 105 & 105 & 105 & 105 & 105 & 114 & 114 & 114 & 114 & 114 & 114 \\
\hline
\end{tabular}

$a_{\text {Rounded to nearest degree. }}$ 


$$
\begin{array}{rlrl}
t & <2 \text { yr: } & \text { PFR } & =1-0.0415 t, \\
2 \leq t & <15 \text { yr }: & \text { PFR } & =0.960-0.0215 t, \\
t & \geq 15 \text { yr: } & \text { PFR }=0.826-0.0125 t .
\end{array}
$$

Salt and salt-plus-shale have temperature-dependent thermal conductivit1es. In the hybrid program these functions are approximated by Eqs. (4) and (5), where $\mathrm{HK}$ is the thermal conductivity in Btu $\mathrm{yr}^{-1} \mathrm{ft}^{-1}$ ${ }^{\circ} \mathrm{F}^{-1}$. These relations are linearized fits to the tabulated values used in the reference digitai calculation and match those values within a few percent:

Salt

$$
\begin{array}{rlrl}
\mathrm{T}_{\mathrm{av}} & <212^{\circ} \mathrm{F}: & \mathrm{HK} & =32636-53.53 \mathrm{~T}_{\mathrm{av}}, \\
212^{\circ} \leq \mathrm{T}_{\mathrm{av}} & <392^{\circ} \mathrm{F}: & \mathrm{HK} & =27787=30.66 \mathrm{~T}_{\mathrm{av}}, \\
\mathrm{T}_{\mathrm{av}} \geq 392^{\circ} \mathrm{F}: & \mathrm{HK}=21491-14.6 \mathrm{~T}_{\mathrm{av}} .
\end{array}
$$

Salt-plus-shale

$$
\begin{array}{ll}
\mathrm{T}_{\mathrm{av}}<349^{\circ} \mathrm{F}: & \mathrm{HK}=21150-21.17 \mathrm{~T}_{\mathrm{av}}, \\
\mathrm{T}_{\mathrm{av}}>349^{\circ} \mathrm{F}: & \mathrm{HK}=17300-10.14 \mathrm{~T}_{\mathrm{av}} .
\end{array}
$$

Where nodes include two or more materials, appropriate averages are taken. As an example, one may consider the lower end of the waste container as shown in F1g. $\dot{H}$. At Luvel 1.0, thr norner nnde includes (vertically) $2 \mathrm{ft}$ of waste and $3 \mathrm{ft}$ of salt. The general assumption ie that heat transfer is taken node point to node point. In this case, where heat generation as well as transmission is involved, the heat transfer is assumed to come from the midpoint of the waste. The heat transfer coefficient $\mathrm{k}$ in the waste is given as $1 \mathrm{Btu} \mathrm{hr} \mathrm{ft}^{-1} \mathrm{ft}^{-1}{ }^{\circ} \mathrm{F}^{-1}=8760 \mathrm{Btu}$ $\mathrm{yr}^{-1} \mathrm{ft}^{-1}{ }^{\circ} \mathrm{F}^{-1}$. That in the salt w1ll be expressed as IIK $\left(\mathrm{T}_{\mathrm{av}}\right)$, as shown above. For the corner, the depth of the node in the $y$-direction is $1 \mathrm{ft}$. The $\mathrm{x}$-direction thermal resistance for the upper $2 \mathrm{ft}$ of the node is then

$$
\begin{aligned}
& \mathrm{R}_{\mathrm{u}}=\sum \frac{\ell}{\mathrm{kA}}=\frac{0.5}{8760(2)}+\frac{1.0}{2 \mathrm{HK}}=\frac{\mathrm{HK}+17520}{35040 \mathrm{Hk}} . \\
& \mathrm{C}_{\mathrm{u}} \equiv \frac{1}{\mathrm{R}_{\mathrm{u}}}=35040 \mathrm{HK} /(\mathrm{HK}+17520) .
\end{aligned}
$$


ORNL-DWG 77-20276

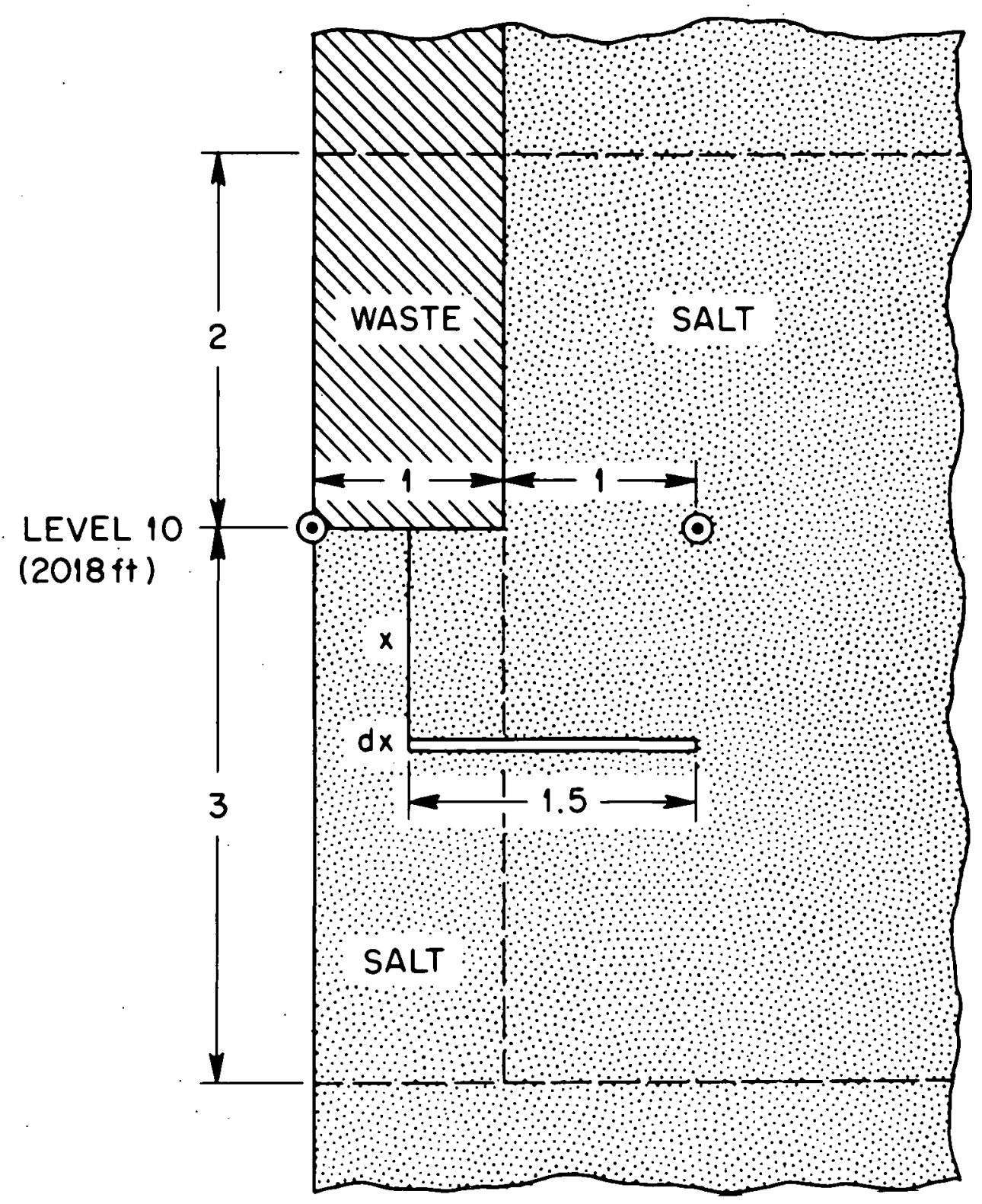

NOTE: DIMENSIONS IN FEET

Fig. 6. Configuration of node at base of waste. 
Heat in the upper $2 \mathrm{ft}$ of the node travels radially from the waste into the salt. Heat in the salt which composes the lower $3 \mathrm{ft}$ of the node derives primarily from the waste; it flows from the bottom face of the waste into the salt, and thence travels both downward and radially into the adjoining nodes. For purposes of quantifying this heat flow in the $x$-direction, the mean distance from the bottom face of the waste to the vertical boundary with the adjacent node is assumed to be $1.5 \sqrt{2}=2.12$ ft. The mean cross-sectional area for heat flow is assigned the value of $2.5 \mathrm{ft}^{2}$. Using these values to calculate the thermal resistance across the salt in the lower $3 \mathrm{ft}$ of the node produces

$$
\mathrm{C}_{\ell}=\frac{\mathrm{kA}}{\ell}=\mathrm{HK} \times 2.5 / 2.12=1.1785 \mathrm{HK} .
$$

Combining the $\mathrm{x}$-direction conductances for the upper and lower portions of the node gives

$$
\mathrm{C}_{\mathrm{T}}=\mathrm{C}_{\mathrm{u}}+\mathrm{C}_{\ell}=[35040 \mathrm{HK} /(\mathrm{HK}+17520)]+1.1785 \mathrm{HK} .
$$

The volumetric heat capacity is $37 \mathrm{Btu} \mathrm{ft}^{-3}{ }^{\circ} \mathrm{F}^{-1}$ for the waste and $2 /$. Btu $f t^{-3}{ }^{\circ} \mathrm{F}^{-1}$ for the salt. The total heat capacity for the node is, therefore, $V c_{v}=(2 \times 37)+(3 \times 27)=155 \mathrm{Btu}{ }^{\circ} \mathrm{F}^{-1}$.

The rate of change of temperature due to heat flow in the $x$-direction is given by

$$
\dot{\mathrm{T}}_{\mathrm{x}} \approx \frac{\mathrm{C}_{\mathrm{T}} \Delta \mathrm{T}}{\mathrm{C}_{\mathrm{V}} \mathrm{V}}=[35040 \mathrm{HK} /(\mathrm{HK}+17520)+1.1785 \mathrm{HK}] \frac{\Delta \mathrm{T}}{155} .
$$

To give a numerical example: if $\mathrm{T}_{\mathrm{av}}=238^{\circ} \mathrm{F}$, by Eq. (4b), $\mathrm{HK}=20,490$ Btu $\mathrm{yr}^{-1} \mathrm{ft}^{-1}{ }^{\circ} \mathrm{F}^{-1}$, making $\mathrm{C}_{\mathrm{T}} / \mathrm{c}_{\mathrm{v}} \mathrm{V}=277.7 \mathrm{yr}^{-1}$. The programmed time scale capacitors give the integrators an inherent gain of $10^{3}$, making 0.2777 the correct setting for the appropriatc attenuator. The digital portion of the hybrid computer would set this value into coefficient device 245 (Fig. 1), which would then operate on the voltage representing $\Delta \mathrm{T}$ between $\mathrm{T}_{11}$ and $\mathrm{T}_{21}$. As the mean temperature of the salt changed in 
this area, local HK would vary, thereby affecting the setting of coefficient 245. Proper material and geometrical properties would be recognized in the setting of each coefficient for all values of $x, y$, and $z$.

\section{DISCUSSION OF RESULTS}

The equilibrium conditions of the repository are upset by two perturbations at the start of the simulation. The first is the burial of hot, power-producing waste along the $z$-axis between the 2010 - and 2018-ft levels. The second is the introduction of a flow of $74^{\circ} \mathrm{F}$ cooling air into an excavated room in which the floor is $10 \mathrm{ft}$ above the top level of the waste canister. One introduction produces heat, the other removes it, with the result that some initial temperatures will go up and others down. Table 4 lists the initial conditions for SALTY and HEATING5. As mentioned previously, SALTY boundary conditions were so chosen as to make the two sets of initial salt temperatures very close to the same.

The computationa1 node points in HEATING5 are more closely spaced than those in SALTY. Among the nodes included in HEATING5 but omitted in SALTY are those which lie along the waste-salt interface. Thus SALTY generates only one waste temperature at each $z$-level, and the closest salt temperature measurements are $1 \mathrm{ft}$ from the waste-salt boundary. To compare the outputs of the two programs, it is destrable to start from as close as possible to the same initial conditions. Since each waste node in SALTY must represent both the salt interface and the centerline waste temperatures of HEATING5, each initial condition for a waste node in SALTY is made a weighted average of the centerline and the interface temperatures used for initial conditions in the reference digital calculation.

'l'he greatest differences between the. two models are as follows: (1) the finer $x-y$ grid structure in the dlyltal version; and (2) the inclusion of thermal radiation from waste to concrete in the hybrid model; and (3) thermal radiation from the excavation fioor to the cavity walls in HEATING5. The results of these differences are intermingled in the temperature discrepancies between the hybrid and digital results. 
To largely separate the effects, temperatures can be examined at a location where fine structure is less important and far enough from the excavation floor to make radiation to the room unimportant. The locations chosen lie along a vertical line in the salt at $y=2 \mathrm{ft}, \mathrm{x}=0$, picking three points adjacent to the waste burial pit at $z=2014 \mathrm{ft}$ (level of the waste midpoint), $z=2010 \mathrm{ft}$ (top of the waste), and $z=$ $2007 \mathrm{ft}$ (bottom of the concrete plug). These are the points in the " $\mathrm{a}$ " boxes shown in Table 5. After two years of simulated heat transfer, SALTY-produced temperatures at these three 1ocations are 288, 226, and $164^{\circ} \mathrm{F}$, respectively, while those for HEATING5 are 296,234 , and $163^{\circ} \mathrm{F}$. When the hybrid program is resum without wacte-to-sonrrete radiation, the corresponding temperatures are 293, 234, and $163^{\circ} \mathrm{F}$, or virtually the same.as for HEATING5. It is clear that the effect of the waste-toconcrete thermal radiation has been isolated, and that at $2 \mathrm{ft}$ from the waste centerline the main effect is to reduce the salt temperature by $7-8^{\circ} \mathrm{F}$.

If temperatures in the waste itself are examined, the effects of the thermal radiation are accentuated, but the finer structure of the digital model in this area also has an effect. For $x=0, y=0$, at. 2 $y r$, and for the same $z$-locations, the hybrid model with radiation gives temperatures of 537,449 , and $183^{\circ} \mathrm{F}$. The digital results are 549,429 , and $165^{\circ} \mathrm{F}$. Because of the radiative heat cransfer, the concrote plug is $18^{\circ} \mathrm{F}$ hotter in the hybrid results, but at $429^{\circ} \mathrm{F}$ the top of the waste is unexpectedly cooler in the digital case. When SALTY is run without waste-to-concrete radiation, the three temperatures are 543, 484, and $159^{\circ} \mathrm{F}$. Comparison of the two sets of hybrid results shows a clear effect of including thermal radiation: the temperature at the top of the waste is decreased $35^{\circ} \mathrm{F}$, and the bottom of the concrete is increased $24^{\circ} \mathrm{F}$. The lower temperalures in the waste notes of HEATING5 appear to result from the cooling effect of thin salt nodes immediately adjacent to the waste; these are provided in HEATING5, but not in the hybrid simulation. As time passes, these thin salt nodes will be heated to almost the temperature of the waste, and their differential effect should become less. 
Table 5. Temperatures $\left({ }^{\circ} \mathrm{F}\right)$ at time $2 \mathrm{yr}$, and taken at the $y=2 \mathrm{ft}$ plane through the waste sample $\mathrm{e}^{\alpha}$

\begin{tabular}{|c|c|c|c|c|c|c|c|c|c|c|c|c|c|}
\hline \multirow{2}{*}{$\begin{array}{l}\text { Elev } \\
\text { (feet } \\
\text { below } \\
\text { grade) }\end{array}$} & \multicolumn{6}{|c|}{$\begin{array}{l}\text { From Hybrid Model } \\
x \text { distance }(\mathrm{ft})\end{array}$} & \multicolumn{7}{|c|}{$\begin{array}{l}\text { From Digital Model } \\
x \text { distance }(\mathrm{ft})\end{array}$} \\
\hline & & 0.0 & 2.0 & 5.0 & 9.0 & 39.0 & & 0.0 & 0.8 & 2.0 & 5.0 & 9.0 & 34.0 \\
\hline 1000 & & 77 & 77 & 77 & 77 & 77 & & 74 & 74 & 74 & 74 & 74 & 74 \\
\hline 1978 & & 82 & 82 & 82 & 84 & 94 & & 89 & 89 & 89 & 89 & 89 & 97 \\
\hline 1982 & & 79 & 79 & 79 & 83 & 96 & & 88 & 88 & 88 & 88 & 86 & 99 \\
\hline 1985 & & 74 & 74 & 74 & 83 & $97^{\circ}$ & & 74 & 74 & 74 & 74 & 84 & 100 \\
\hline 1988 & & 74 & 74 & 74 & 84 & 99 & & 74 & 74 & 74 & 74 & 83 & 102 \\
\hline 1991 & & 74 & 74 & 74 & 87 & 100 & & 74 & 74 & 74 & 74 & 84 & 104 \\
\hline 1994 & & 74 & 74 & 74 & 91 & 102 & & 74 & 74 & 74 & 74 & 86 & 106 \\
\hline 1997 & & 74 & 74 & 74 & 96 & 104 & & 74 & 74 & 74 & 74 & 90 & 108 \\
\hline 2000 & $\mathrm{~b}$ & 108 & 112 & 104 & 104 & 107 & $\mathrm{~b}$ & 96 & 96 & 96. & 95 & 97 & 111 \\
\hline 2001 & & 114 & 115 & 110 & 108 & 108 & & 104 & 104 & 104 & 103 & 103 & 112 \\
\hline 2003 & & 127 & 126 & 121 & 116 & 110 & & 121 & 120 & 120 & 117 & 114 & 113 \\
\hline 2007 & & 164 & 159 & 146 & 131 & 114 & & 163 & 162 & 159 & 148 & 135 & 117 \\
\hline 2010 & $\mathrm{a}$ & 226 & 199 & 166 & 140 & 117 & $a$ & 234 & 228 & 209 & 173 & 149 & 119 \\
\hline 2014 & & 228 & 238 & 185 & 149 & 120 & & 296 & 286 & 252 & 195 & 161 & 122 \\
\hline 2018 & & 233 & 211 & 180 & 153 & 122 & & 241 & 237 & 222 & 188 & 163 & 124 \\
\hline 2024 & & 164 & 162 & 157 & 149 & 124 & & 168 & 168 & 167 & 162 & 154 & 126 \\
\hline 2040 & & 132 & 132 & 131 & 130 & 119 & & 133 & 133 & 133 & 133 & 131 & 123 \\
\hline 3000 & & 105 & 105 & 105 & 105 & 105 & & 114 & 114 & 114 & 114 & 114 & 114 \\
\hline
\end{tabular}

$a_{\text {Rounded to nearest degree. }}$ 
Table 5 presents 2-yr temperatures for SALTY and for HEATING5, taken at the $\mathrm{y}=2 \mathrm{ft}$ plane. Temperatures in the area adjacent to the waste deposit have been discussed previously, and their values are compared in the boxes labeled "a." As demonstrated previously, when thermal radiation from the waste is omitted from the hybrid model, SALTY results in this area are almost identical to those from HEATING5. Results diverge in the area of the repository floor, where the hybrid model shows temperatures $12^{\circ} \mathrm{F}$ higher. These temperatures are compared in the boxes labeled "b." Investigation shows that almost all of this difference is due to omitting the thermal radiation term from the repository floor heat balance in the hybrid model. At zero time the radiation term is indeed negligible. However, as the floor heats up, the fourth-power radiation term can represent a significant fraction of total heat loss to the room, and this vigorous nonlinear feedback limits the temperature difference between the floor and its surroundings. Should the hybrid program be pursued, it would be desirable to include terms for radiation from the repository floor. Because of the limited range of temperatures assumed by the floor, ceiling, and walls, the approximation $\left(\mathrm{T}_{1}^{4}-\mathrm{T}_{2}^{4}\right) \simeq \mathrm{K}_{\mathrm{T}}\left(\mathrm{T}_{1}-\right.$ $\mathrm{T}_{2}$ ) holds even closer here than it did in the case of waste-to-concrete radiation. The view factor from the floor to the ceiling is 0.3125 , and $\mathrm{K}_{\mathrm{T}}$ for the temperatures involved is $22.09 \times 10^{8}{ }^{\circ} \mathrm{R}^{3}$. This yields a floor-to-ceiling heat flux of

$$
\dot{\mathrm{H}}_{\mathrm{c}} \simeq 2845\left(\mathrm{~T}_{\text {floor }}-\overline{\mathrm{T}}_{\text {ceiling }}\right) \text { Btu } \mathrm{yr}^{-1} \mathrm{ft}^{-2} \text {. }
$$

The view factor from the floor to the wall is about 0.38 , and $\mathrm{K}_{\mathrm{T}}$ for those temperatures is $2.63 \times 10^{8}{ }^{\circ} \mathrm{R}^{3}$. This gives a floor-to-wall heat flux of

$$
\dot{\mathrm{H}}_{\mathrm{w}} \simeq 3574\left(\mathrm{~T}_{\text {floor }}-\overline{\mathrm{T}}_{\text {wa11 }}\right) \text {. }
$$

To add these relations to the hybrid program in a continuously varying analog fashion would require an additional digital coefficient unit (DCU) for each cavity-abutting node, for a total of 16 DCUs. 
The available HEATING5 printout stops at $3 \mathrm{yr}$, at which time its output has not changed drastically from the 2 -yr values. In the hybrid model the bottom of the concrete plug peaks at $184^{\circ} \mathrm{F}$ at $3 \mathrm{yr}$, and the repository floor temperature peaks at about $109^{\circ} \mathrm{F}$ at $4 \mathrm{yr}$. In the absence of a thermal radiation term, all floor temperatures must be considered to be too high. At $8 \mathrm{yr}$ the peak waste temperature is $480^{\circ} \mathrm{F}$; the floor temperature is $108^{\circ} \mathrm{F}$. At $15 \mathrm{yr}$ the peak waste temperature is $393^{\circ} \mathrm{F}$; the floor temperature is $103^{\circ} \mathrm{F}$.

Table 6 shows the outputs of two hybrid runs at $30 \mathrm{yr}$. The data labeled "Standard Hybrid Results" are from the as-formulated SALTY program described in this report. The "Digital Input Hybrid Results" are from a hybrid run without waste-to-concrete thermal radiation and started from the HEATING5 initial temperatures and boundary conditions. The data in the "a" boxes show that the top of the waste is cooler and the bottom of the concrete is hotter where radiative heat transfer is included, but that these two temperatures are the only ones significantly affected. Floor temperatures in the " $b$ " boxes are almost identical in the two data sets, and, for reasons previously established, can be considered to be a few degrees too high. As indicated, inclusion of a radiation term would be desirable at the repository floor. Differences at the $3000-\mathrm{ft}$ level reflect the inequality of boundary conditions in the two models.

Running time of the hybrid program (for 30-yr simulations) was reduced from $5.5 \mathrm{hr}$ to slightly over $3 \mathrm{hr}$ by judicious manipulation of the time steps. The final schedule of time steps is that shown in Table 3. A reduction of another hour could very likely be achieved by increasing the $0.0025-\mathrm{yr}$ time step to $0.0060 \mathrm{yr}$ after IT $=514$, possibly including some step-to-step averaging to increase stability.

SALTY was written as an exploratory test program to determine the usefulness of the hybrid approach to spatially extended heat transfer problems. It was not optimized for minimum running time, nor was it programmed for flexibility in terms of callable options. However, even as it stands, the hybrid program SALTY provides reasonable approximations to HEATING5 results in about $20 \%$ of the running time and on a 10 
times cheaper machine. (It should be recognized that the sample HEATING5 calculation solved a $7 \times 13$ node $x-y$ matrix, SALTY only $4 \times 5$.) Where changes in the model were required, local reprograming did not prove a difficult task. For problems of the type described, the hybrid approach provides a useful alternative to digital programming.

\section{REFERENCES}

1. W. D. Turner, D. C. Elrod, and I.' I. Siman-Tov, HEATING5 - An IBM 360 Heat Conduction Progrom, ORNL/CSD/TM-15 (March 1977).

2. W. H. MsAdams, Heat Transmission; McGraw-Hil1, New York, 1954 , Figs. 4-10 and 4-11. 
Table 6. Temperatures $\left({ }^{\circ} \mathrm{F}\right)$ at time $30 \mathrm{yr}$, and taken at the $y=0$ plane through the waste sample $e^{a}$

\begin{tabular}{|c|c|c|c|c|c|c|c|c|c|c|c|c|}
\hline \multirow{2}{*}{$\begin{array}{l}\text { Elev } \\
\text { (feet } \\
\text { below } \\
\text { grade) }\end{array}$} & \multicolumn{6}{|c|}{$\begin{array}{c}\text { Standard Hybrid Results } \\
\mathrm{x} \text { distance }(\mathrm{ft})\end{array}$} & \multicolumn{6}{|c|}{$\begin{array}{c}\text { Digita1-Input Hybrid Results } \\
\mathrm{x} \text { distance }(\mathrm{ft})\end{array}$} \\
\hline & & 0.0 & 2.0 & 5.0 & 9.0 & 39.0 & & 0.0 & 2.0 & 5.0 & 9.0 & 34.0 \\
\hline 1000 & & 79 & 79 & 79 & 79 & 79 & & 76 & 76 & 76 & 76 & 76 \\
\hline 1978 & & 79 & 79 & 79 & 80 & 89 & & 80 & 80 & 80 & 81 & 91 \\
\hline 1982 & & 77 & 77 & 77 & 80 & 91 & & 77 & 78 & 78 & 80 & 93 \\
\hline 1985 & & 74 & 74 & 74 & 80 & 93 & & 74 & 74 & 74 & 81 & 94 \\
\hline 1988 & & 74 & 74 & 74 & 81 & 94 & & 74 & 74 & 74 & 82 & 95 \\
\hline 1991 & & 74 & 74 & 74 & 83 & 96 & & 74 & 74 & 74 & 84 & 97 \\
\hline 1994 & & 74 & 74 & 74 & 85 & 98 & & 74 & 74 & 74 & 86 & 99 \\
\hline 1997 & & 74 & 74 & 74 & 89 & 100 & & 74 & 74 & 74 & 90 & 101 \\
\hline 2000 & $b$ & 92 & 95 & 93 & 94 & 102 & b & 93 & 95 & 94 & 95 & 103 \\
\hline 2001 & & 98 & 99 & 97 & 97 & 103 & & 99 & 99 & 98 & 98 & 104 \\
\hline 2003 & & 107 & 106 & 104 & 102 & 104 & & 107 & 107 & 105 & 103 & 106 \\
\hline 2007 & & 134 & 126 & 118 & 111 & 108 & & 124 & 126 & 120 & 113 & 109 \\
\hline 2010 & a & 255 & 154 & 131 & 118 & 110 & a & 269 & 157 & 133 & 119 & 112 \\
\hline 2014 & & 291 & 182 & 143 & 124 & 113 & & 294 & 184 & $: 145$ & 126 & 115 \\
\hline 2018 & & 209 & 162 & 142 & 128 & 116 & & 212 & $165^{\circ}$ & 144 & 131 & 118 \\
\hline 2024 & & 137 & 136 & 134 & 130 & 119 & & 140 & 139 & 136 & 132 & 122 \\
\hline 2040 & & 129 & 129 & 129 & $128^{\circ}$ & 124 & & 132 & 132 & 132 & 131 & 127 \\
\hline 3000 & & 106 & 106 & 106 & 106 & 106 & $\therefore$ & 116 & 116 & 116 & 116 & 116 \\
\hline
\end{tabular}

$a_{\text {Rounded to nearest degree. }}$ 


\section{THIS PAGE}

\section{WAS INTENTIONALLY \\ LEFT BLANK}


APPENDIX A

DIGITAL LISTING OF SALTY PROGRAM 


\section{THIS PAGE}

\section{WAS INTENTIONALLY \\ LEFT BLANK}


Appendix $A$ :

ᄂ

PRgLRAM SALIY: KEVISED CIZZII8"OAB

し

DIMENSION IAD(OO), IVU (OB), IAP( IS) IVF(75), TEMORT $(5,4,31,31)$

1 ,GUP(SI), GDN(31), GX(4),GY(S), JAOB $(63)$. ITEYPT $(5,4)$, TEMP $(5,4,31)$

1,IVT (J3), YPLN.(4), ZDIST.(4u), IVAL $(.68), I 4 P 3(75), 1$ AMP (80), I AMPB (80)

$\checkmark$ TEMPER( $5,4,31), \theta Z H T(18)$

WKITE(S, UU)

I0 FURMAT( IS ANALOL REAUYZ TYYE I FIR YES. II)

I RLAD(S, ¿U) IANSW

20 FURMAT $(1 \downarrow)$

IF (IANSW-1) $1,2,1$

2 CONTINUE

CALL INITACU,UU)

OHEN (UNIT = IO,DEVICE = USKO',FILE='STURI. LAT')

c

KEAD DATA IROM DISKU FILE 'STOKI,UAT'.

READ(1O,SU) NUAC, NPUT, NAUC, NAMP

30 FORMAT.(1216)

$\operatorname{REAU}(1 U, S U)(I A D(J U), I V D(J D), J U=1, N U A C)$

REAU (IO,SU) (IAP (JP), IVP(JP),JP = I,NPgT)

REAU $(1 U, S U)$ I AMP

REAL(IU, 4U) TEMH

40 FORMAT (1UF 6.2$)$

READ (10.1 IUU) GUR

ISO FORMAT.( $४ F \mid U . .5)$

REAUP(10, ISU) LIDN

REAU $(I U, I D U)$ GX

READ (10,1DU) GY

REAU $(10,4 U)$ YPLN

REAU $(10,4 U)$ ZUIST

CLOSE ( UNIT = I O, DEVICE = USKO', FILE ='STEZI:DAT')

DO $204 J=1$, NAMP

CALL ADUR(IAMP(J), IAMPQ(J))

CALL MUKPHY (IAMHB(J),M)

It (M) $210,200,210$

210 WKITE(5,YU) IAMH(J)

200 CONTINUE

CALL ADUR $(022 U, 1 A U C)$

DU $32 L=1$, NUAC

CALL ADUR( IAU(L), IAUB (L))

CALL MUKPHY (IADO $(L), M)$

It (M) $11 U, 32,11 U$

110 WKITE( 5,90$)$ IAD(L)

GU FURMAT (I0.3X, IINVALIU,/)

32 CUNTINUE

$\iota$

MAKE PKOVISION FOR UTILIZING PAUSES IN PROGRAM. WKITE $(3$, ! $D U U)$

ISUO FORMAT(: DO YOU WISH TO SET POTSZ TYPEI EOR YES.1/)

REAU(b, $\angle U)$ IPOT.

WKITE( $5,2 U)$

SU FOKMAT(" TYPE I FOK PAUSES, U HUK MINIMAL PAUSES $\%$,

REAU(b, $\angle U)$ IPAU

L STURE INITIAL TEMPERATURE VALUES + gK PZIVTHUT.

Du bl $1 J=1,31$

DU b. I I $Z=1,4$

DU bI $I 1=1,0$

b) $\operatorname{TEMPRT}(11,12,13,1)=\operatorname{TEMP}(11,12,10)$

CALL RUN(U)

$\checkmark$ PUT ANALOG COMPUTER IN INITIAL CUNDITIgN MODE.

CALL SETWB(U.29)

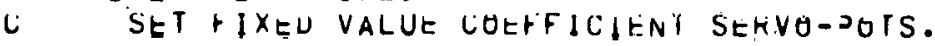




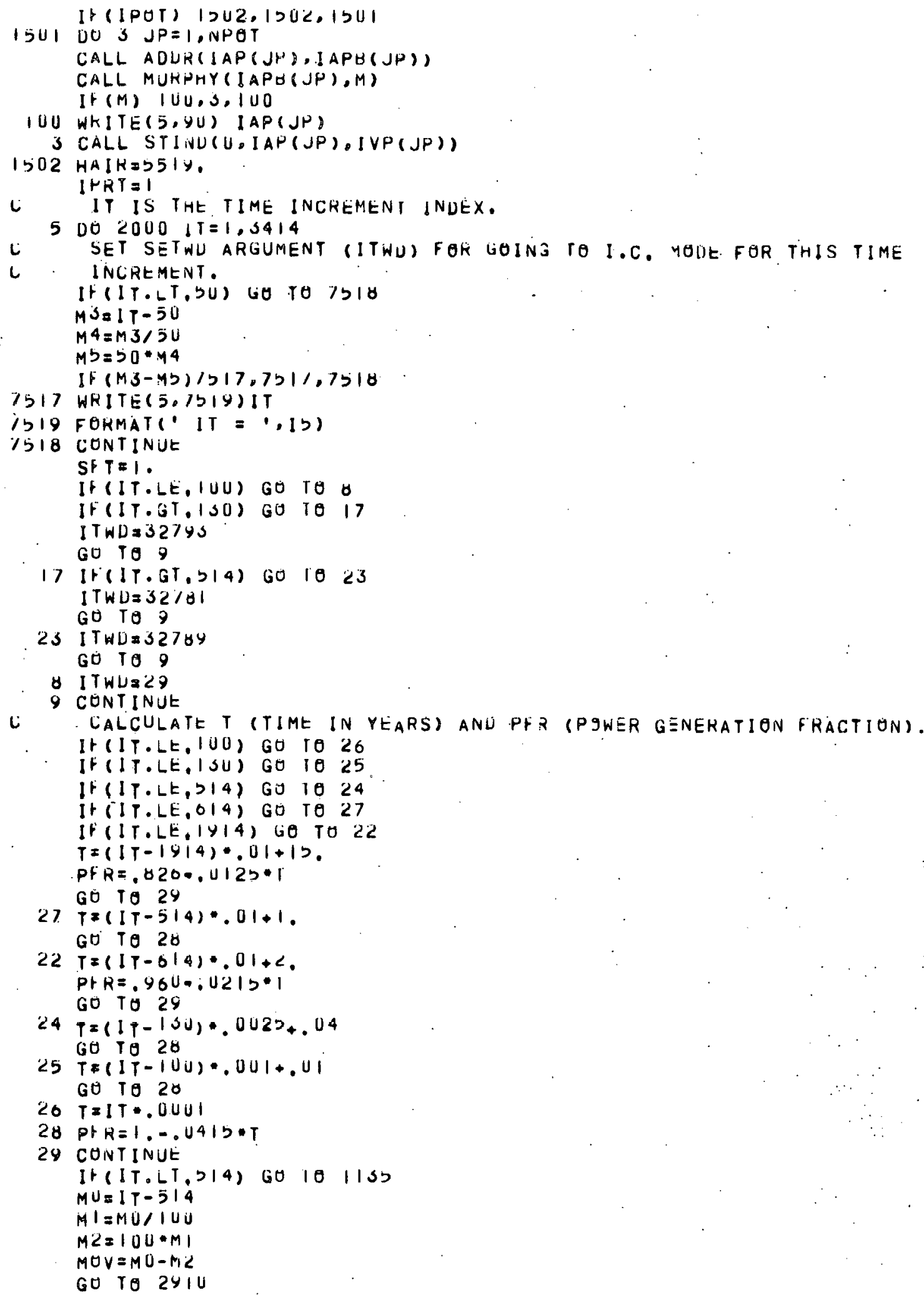




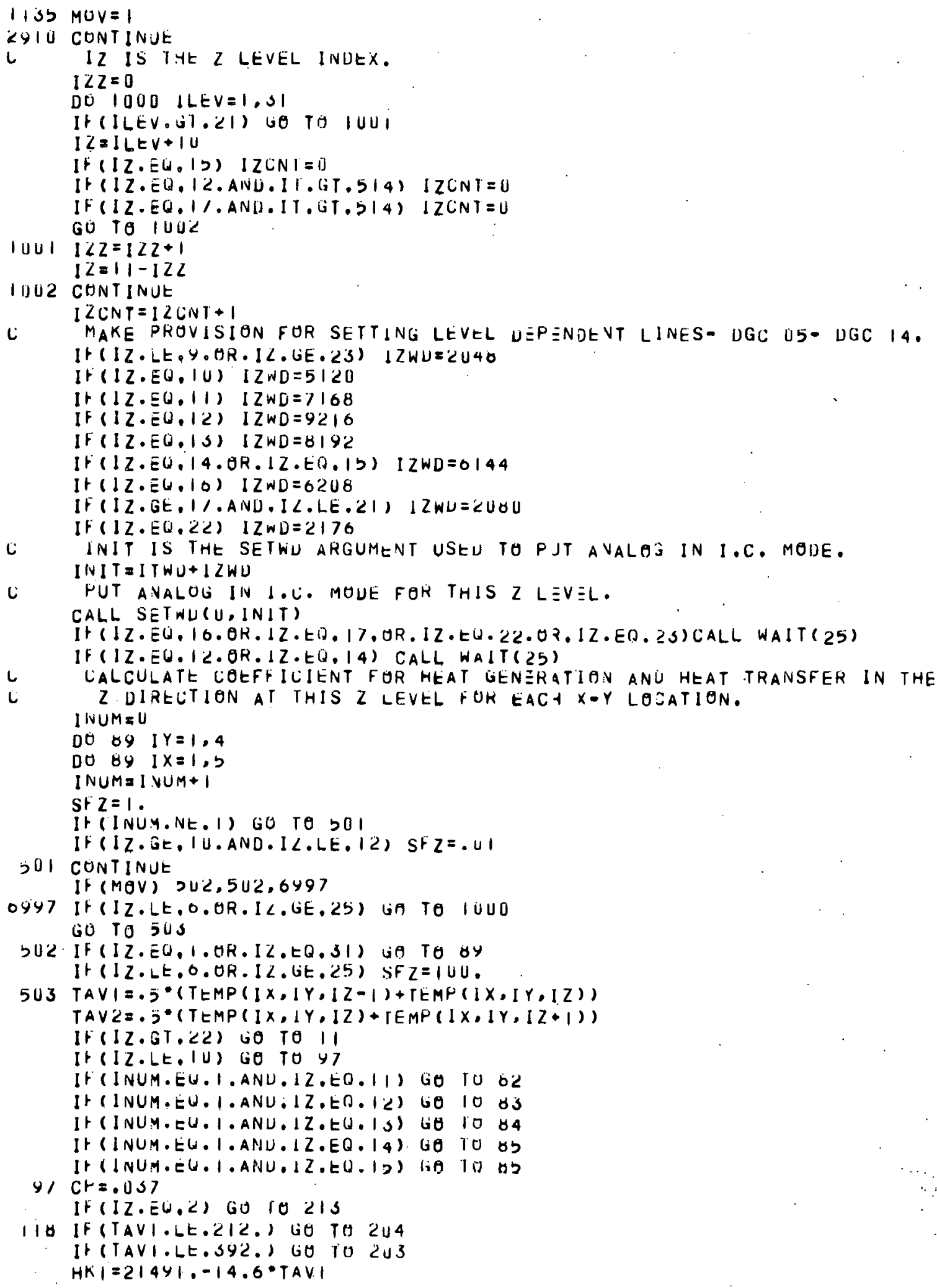


GO TO 200

2US HKI $=2778 / .50 .60$ TAVI

GO TO.20

204 .HKI $=32630 .-33.53$ "TAVI

GO TO 2 US

$21.3 \quad H K 1=1283 \mathrm{U}$

ZUS CONTINUt

If (IZ.EO, 22)GO TO 211

If (TAVZ.LE.212.) GO TO 247

IF (TAVZ.LE.392.) GO TO $2 \cup 6$

HK2 $=21491,-14.6^{\circ}$ TAV 2

Go TO $20 \mathrm{H}$

206 HK2 $=27787,-30.60$.TAVL

GO. TO 200

$247 \cdot H K 2=32650 .-33.53 \cdot T A V 2$

BO TO 200

$11 C P=.03350$

IH (TAVI,LE.349, ) LO TO 2 U9

$H K|=| / 3 U U .=10.14$ TAVI

GO 10211

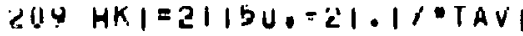

LII CONIINUE

IH (TAV2.LE.S4Y,) LO TO 212

$H K 2=1 \% 3 U U,-10.14 * T A V 2$

GO TO $2 U 8$

212 HK2 $=2115 U .-21 \cdot 11+T A V 2$

208 CONTINUE

$Z H T I=H K I \bullet G U P(I Z) *(T E M P(I X, I Y, I Z-1)-T E M P(I X, I Y, I Z))$

IF (INUM.EO.I. ANU.1Z.EO.IU) LO TU BO I

$Z H T 2=H K L$ LUUN $(I Z) *(T E M P(I X, I Y, I Z+I)-\operatorname{TEMP}(I X, I Y, I Z))$

$95 Z H T=(Z H T 1+Z H T 2) \cdot C H \cdot 2$. SF $L$ SFT

IZHT $=I F I X(Z H T)$

$I V D(I N \cup M)=I Z H T$

If $(1 Z, E, 0,10)$ is 0 iी 80

IF $(1 Z . E O .22)$ GO TO YI

IF (IZ.GE, II.AND, IZ.LE.ZI) GO TO Y.Z

GO TA BY

8) $P W R=P F R * 1.8680 E 0$

$C P I=.032<0$

$H K 2=8764$

$Z H T 2=H K Z \cdot G U N(I Z) *(T E M P(I X, I Y, I Z+1)-T E M P(I X, I Y, I Z))$

$Z H T=(Z H T I+Z H T Z+H W R) \cdot C P \mid \cdot 2$. $=S F Z \cdot S F T$

GO TO $|S|$

O2 $P W R=P F R \cdot 1.2014 E D$

$C P I=.021$

$H K I=8760$.

$H K 2=876 \mathrm{C}^{\circ}$.

60 TO 86

$63 P W R=P F R * 1.2014 E$ ?

$\mathrm{CHI}=.021$

$H K I=8760$,

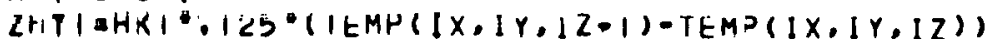

$Z H T=(Z H T I *(P I+P W R) * 2, S F \angle * S F T$

GO TO $\mid 31$

04. $C P I=.0204$

$H K 2=|S| 40:$

$Z H T 2=H K 2 *, 125 *(\operatorname{TEMP}(1 X, I Y, I Z+1)-I E M P(I X, I Y, I Z))$

$\bar{Z} H \bar{T}=2 H T 2 * C H 1 * 2$. SFZ*SFT

GO TO $|3|$

85 SPI $=.0284$ 


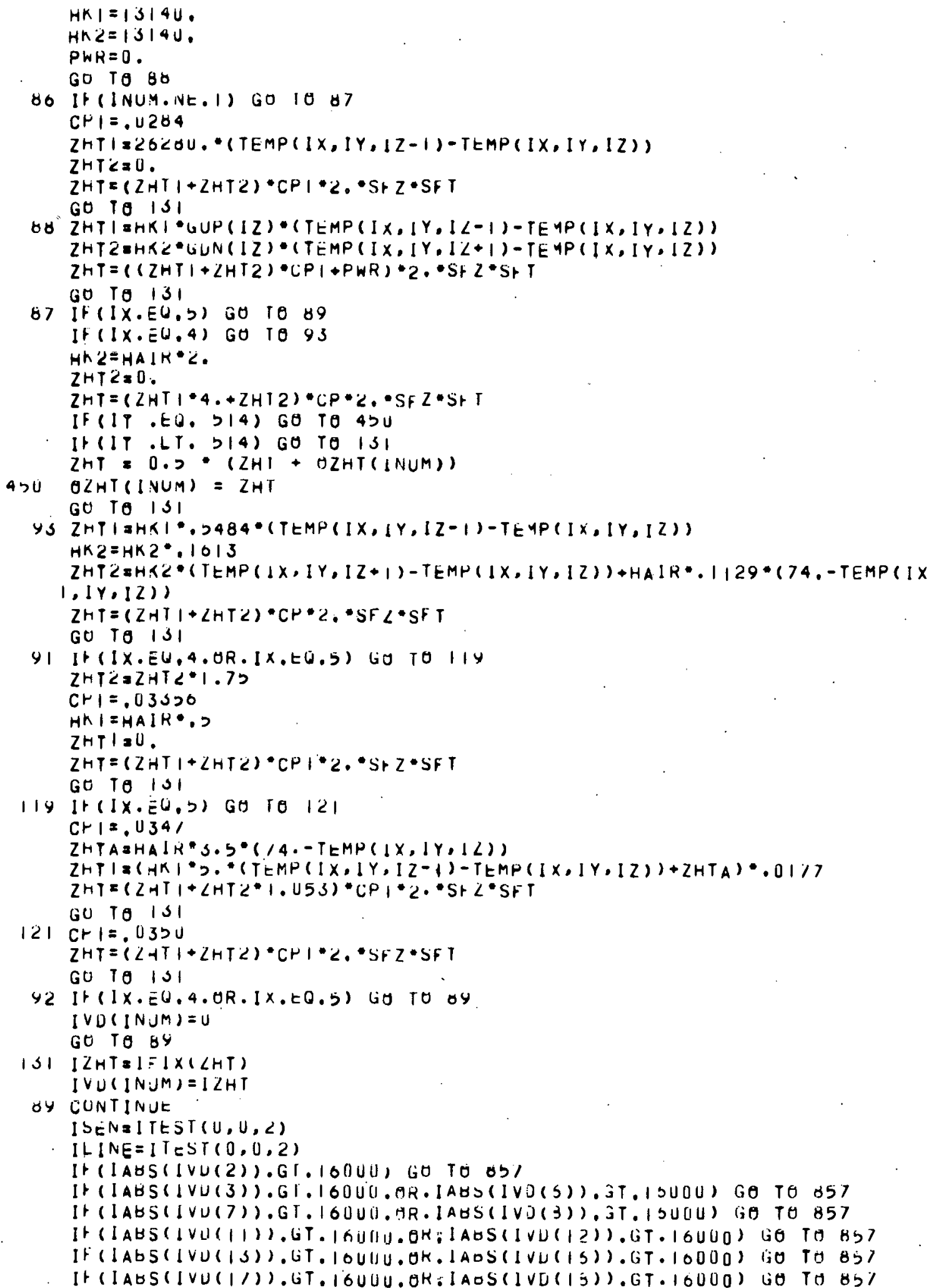




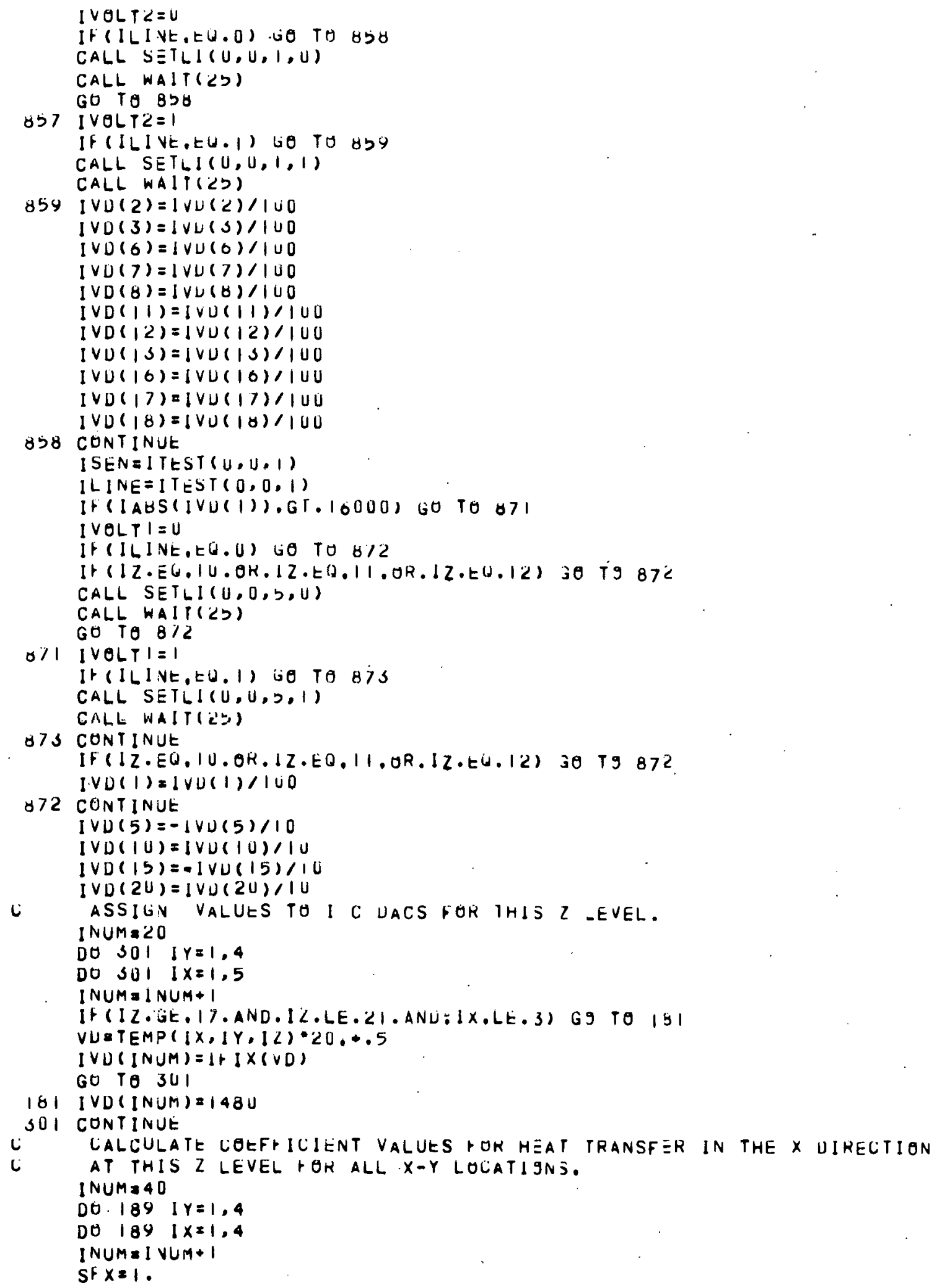


IH (IZ.GE.1/.AND.1Z.LE.2I.AND:IX.LE.Z) Gg TO 192 IF ( IZ.GE. I/.AND.1Z.LE.2I.AND:IX.EO.3) G9 TO I 3

TAV.$J *(T E M P(I X, I Y, I Z)+T E M P(\mid X+1, I Y, I Z))$

IF (IZ.GT.22) GO TO 111

IF (12.EQ.22.AND. IX.NE..4) GO TO III

$C P=.037$

IF (TAV.LE.212.) GO TO SUA

IF (TAV.LE.S92.) GO TO SOS

HK I $=21491 .-14.6$.TAV

GO TO 3 US

$303 \mathrm{HK} /=27767 .-30.60 \cdot \mathrm{TAV}$

GO TO 305

$304 \mathrm{HK} / 232636 .-33.55 * \mathrm{TAV}$

305 IF (IZ.NE. 22) GO TO 307

HK IT:HK I.

II $\mathrm{CP}=.03356$

IF (TAY.LE.S49.) GO TO SOY

$H K 1=1730 U .=10.14 * T A V$

GO. TO 306

$309 H K 1=2115 U_{0}-21.1 / \cdot T A V$

306 IF (IZ.EU.22.AND.IX.EQ.4) HKIEHKIT*.4236+HKI*.57I4

SUT C.ONTINUE

IF (INUM.EO.41.AND.IZ.EO.1।) GO TO 192

I $(I N U M \cdot E 0,41, A N D, 12, E 0.12) \quad 60$ TO 132

IF (INUM.EO.41.AND.12,EU.13) 80 TO 134

IF (INUM.EO.41.AND.IZ,EQ.14) GO TO 134

If (INUM.EO.41, AND. IZ,EQ.15) 60 TO 194

$X H T=H K I * G X(I X) * C P * 10, * S F X * S F T$

$I X H T=I F I X(X H T)$

I $V D(I N U M)=I X H T$

It $(I Z, E 0,16)$ GO TO 186

IF (IZ,EQ.22) LO TO 191

IF (INUM.EU, 4 I.AND.IZ,EQ, IO) GO TO 431 GO 10189

$481 \times H T:(.1 * H K I+6 U 0) * S F X * S F$.

GO TO 180

182 XHT: $1.1(.00005708+1 . / H K 1) * .27 * S F X * S F T$ GO TO 186

187 IF (IX.NE, 3) GO TO I 89

$X H T=H K 1 \div . O U 140 * 10$. SF $X \bullet S H T$

GO TO 180

192 IVD(INUM) $=U$

GO TO 189

$193 \mathrm{CP}=.037$

$X H T=H A I F *, U 1214 * 10 . \cdot S F X * S F T$

GO 10188

184 XHT $=1.1 .(., U U U 0761+1 . / H K 1) \cdot .284 \cdot S F X \cdot S F T$

GO TO 180

186 IF (INUM.IVt.4I) LO TO 187

$X H T=1.1($, UUU076I+1./HKI)*.284*SFX*SFT

GO TO 180

191 It (IX.NE.S) GO TO 197

$X H T=H K 1 * . U U 297 * 10 . \cdot S F X * S+T$

GO TO 180

$|Y|$ IF(IX.NE, 4$)$ GO IO IOY

$X H T=H K 1 *, U U O O / 8 * 1 U . \cdot S F X * S F T$

$188[X H T=I F I X(X H T)$

IVD (INUM) $=\mid X H T$

189 CONTINUE

L CALCULATE COEFPILIENT VALUES POR HEAT TRANSF ER IN THE Y DIRECTION 
AT THIS 2 LEVEL TOR ALL X-Y LOLATISNS. INUM $=56$

Do $289 \quad$ I $x=1.4$

DO $289 \quad 1 Y=1.3$

I NUM $=$ I $N U M+1$

SF $Y=1$.

TAV $=.3 *(T E M P(1 X, \mid Y, I Z)+T E M P(1 X, I Y+1, I Z))$

IF (IZ.EQ.2Z.AND.IX.NE.4) GO TO $4 I I$

IF (IZ.GT.22) LO TO 411

$C P=037$

IF(TAV.LE.212.) GO TO 404

IF (TAV.LE.SY2.) GO TO $40 \mathrm{~S}$

$H K I=21491 .-14.6 * T A V$

GO TO $40 \overline{5}$

$403 \mathrm{HK} I=2778 \% .-30.60 * \mathrm{TAV}$

GO TO $40 \supset$

404 HKI $=32636,-53.53 \cdot T A V$

405 IF (IZ,NE. 2L) GO TO 407 HKIT $=H K I$

$411 \mathrm{CP}=.03356$

IF (TAV.LE.S49.) GO TO $40 Y$

HK I. 173 UU.-10.014.TAV

GO TO 4 U०

$409 H K 1=21150,-21.1 \%$ TA.V

406 IF (IZ.EQ, L2.AND.IX.EQ.4) HKT\$.6UI8*.1KI+.3982*4KIT

407 CONTINUE

It (IZ.GE, II.AND.IZ.LE.21) GO TO 29.2

IF (INUM.NE. 57 ) LO TO 285

If $(12 . E 0.11)$ GO TO 282

It $(12, E 0,12)$ GO TO 282

IF (IZ.GE, IS.AND.IZ.LE. 16) GO TO 284

285. CONTINUE

YHT=HKI*GY(IY)*CP*IU, SSFY SFT

(YHT IIFIX(YHT)

I $V D(I N \cup M)=I Y H T$

IF (INUM.EO.S7.AND.IZ,EQ, 10) GO TO 281

IF (IZ,EO,2Z) GO TO 291

GO TO $28 Y$

281 YHT:(.1*HKI+6UO.)*SFY*SFI

GO TO 208

282 YHT $=1 . /(., U U 057 U 8+1 . / H K I) * .27 * S F Y+S F T$

GO TO 288

284 YHTE $=1.1(.0 U 00 \% 61+1 . / H K I) \cdot .284 \circ S F Y$ SFT GH TO 268

291 IF $(I X, N E, 4)$ GO TO 289

IF (IY.EO, I) GO TO 243

IF(IY.EQ,2) GO TO 242

YHT $=H K T *, U U 248 \cdot 10$. SFY*SFT

GO TO 288

$242 Y H T=H K T \cdot . U U 87 \cdot 1 U$. SFY・SFT

GO TO 286

243 YHT $=H K T * . U 174$ (U.०SFY*SFT

288 IYHTAIFIX(YHT)

IVD(INUM) $=$ IYHT

GO TO 284

292 IF (IX.EO,4) GO IO 289

IVD(INUMI $=U$

289 CONTINUE

IH (1Z.GT.O.ANU.1Z.LT.ZZ) GO TO $7 / 2$

DO $773 \quad I U=2,2 U$ 


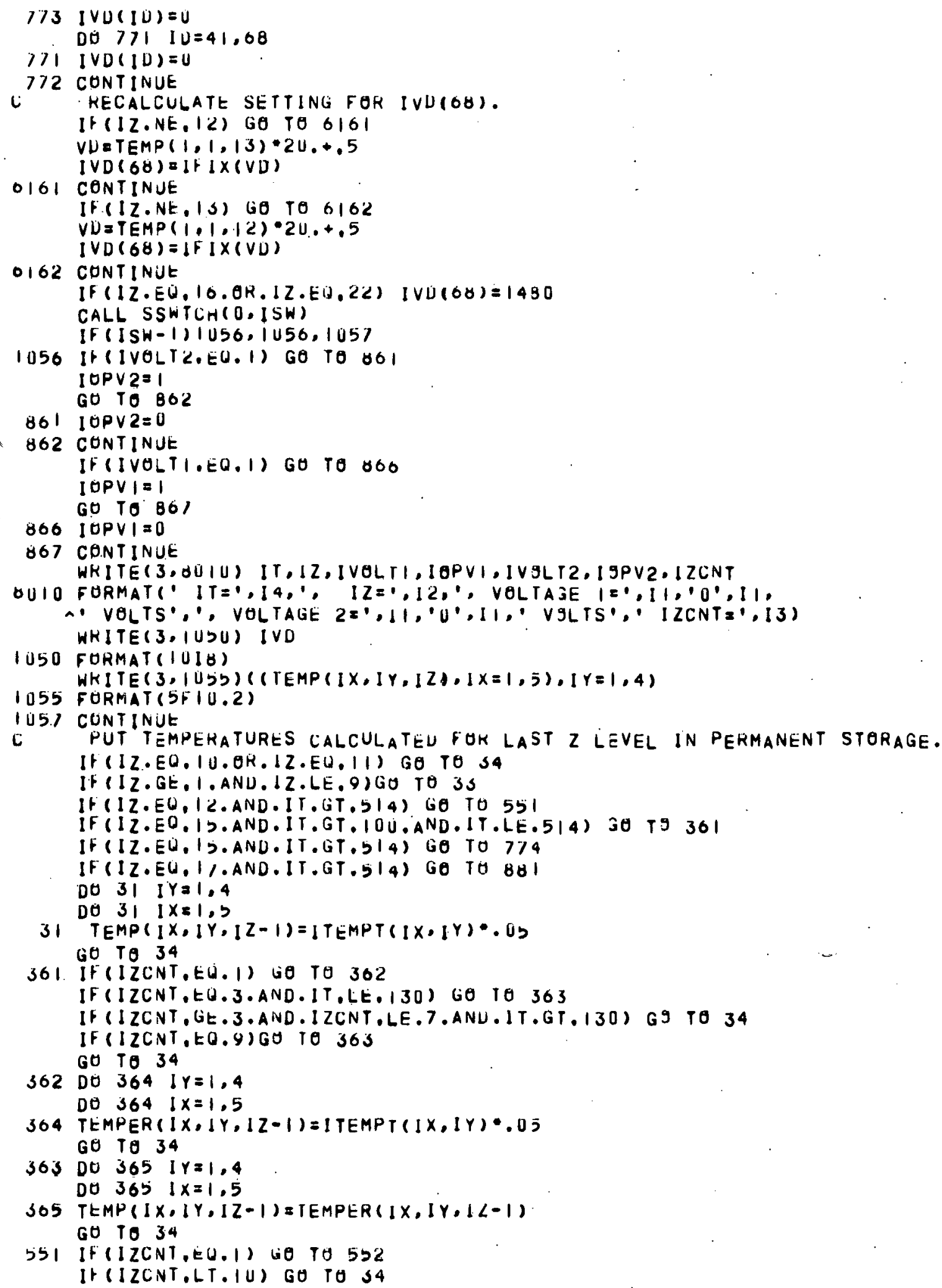




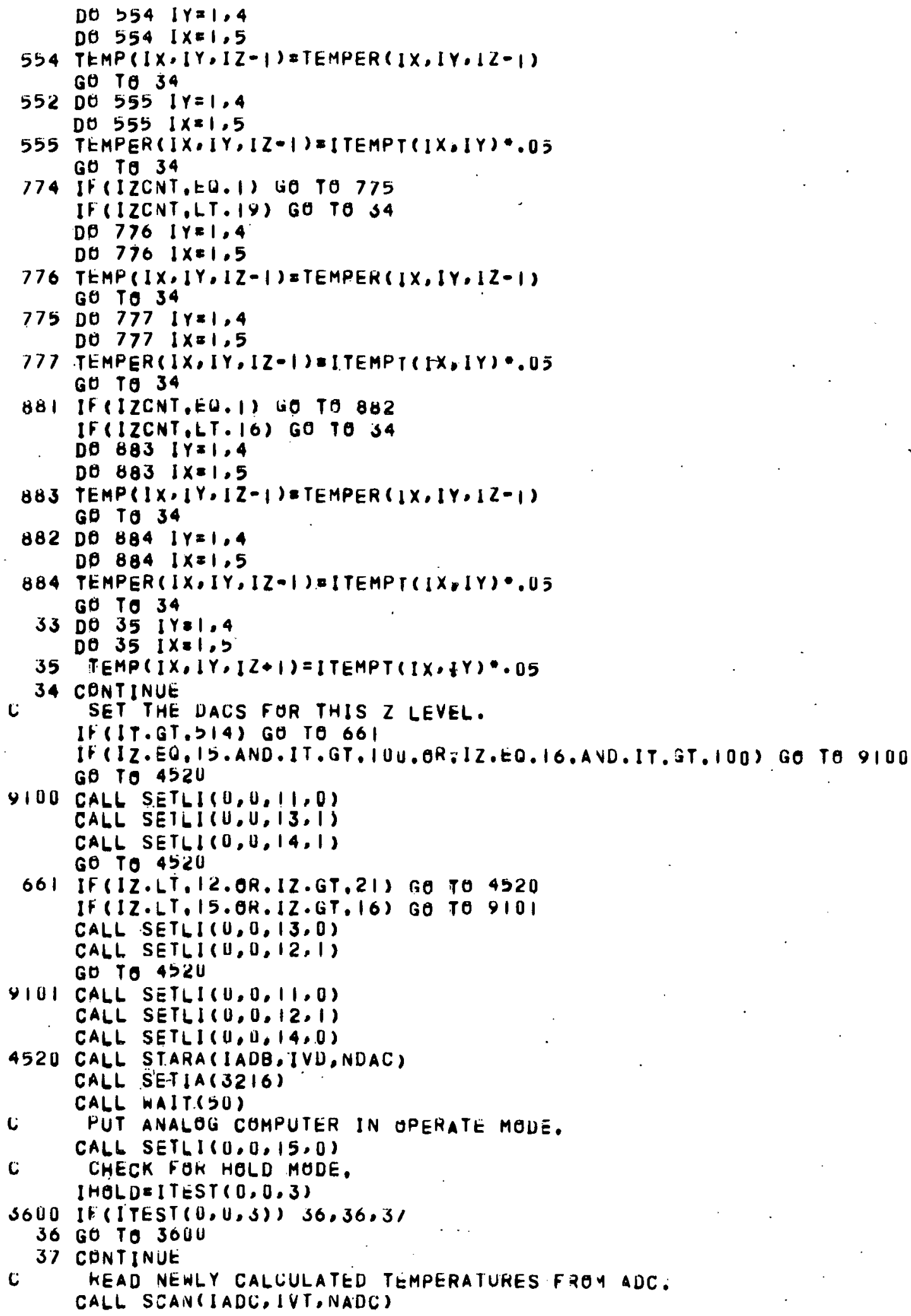




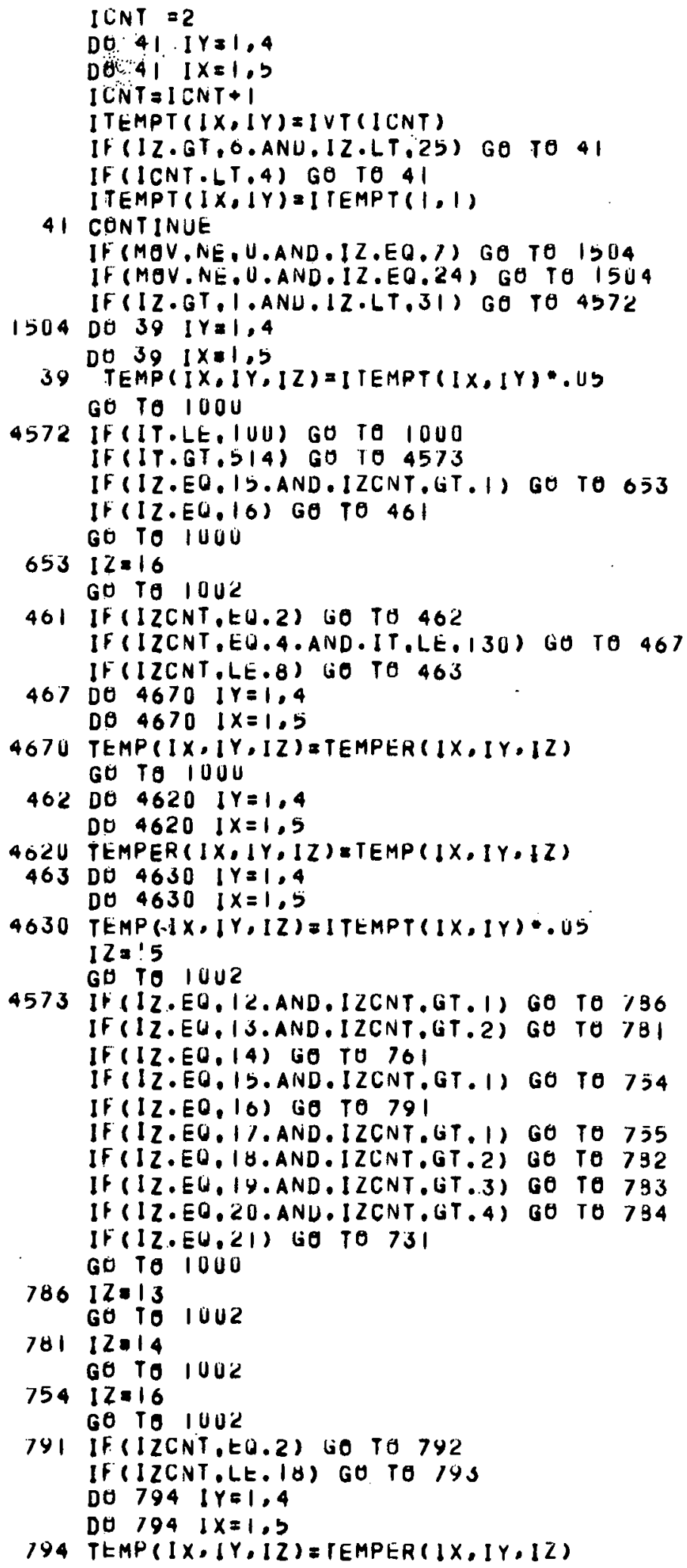




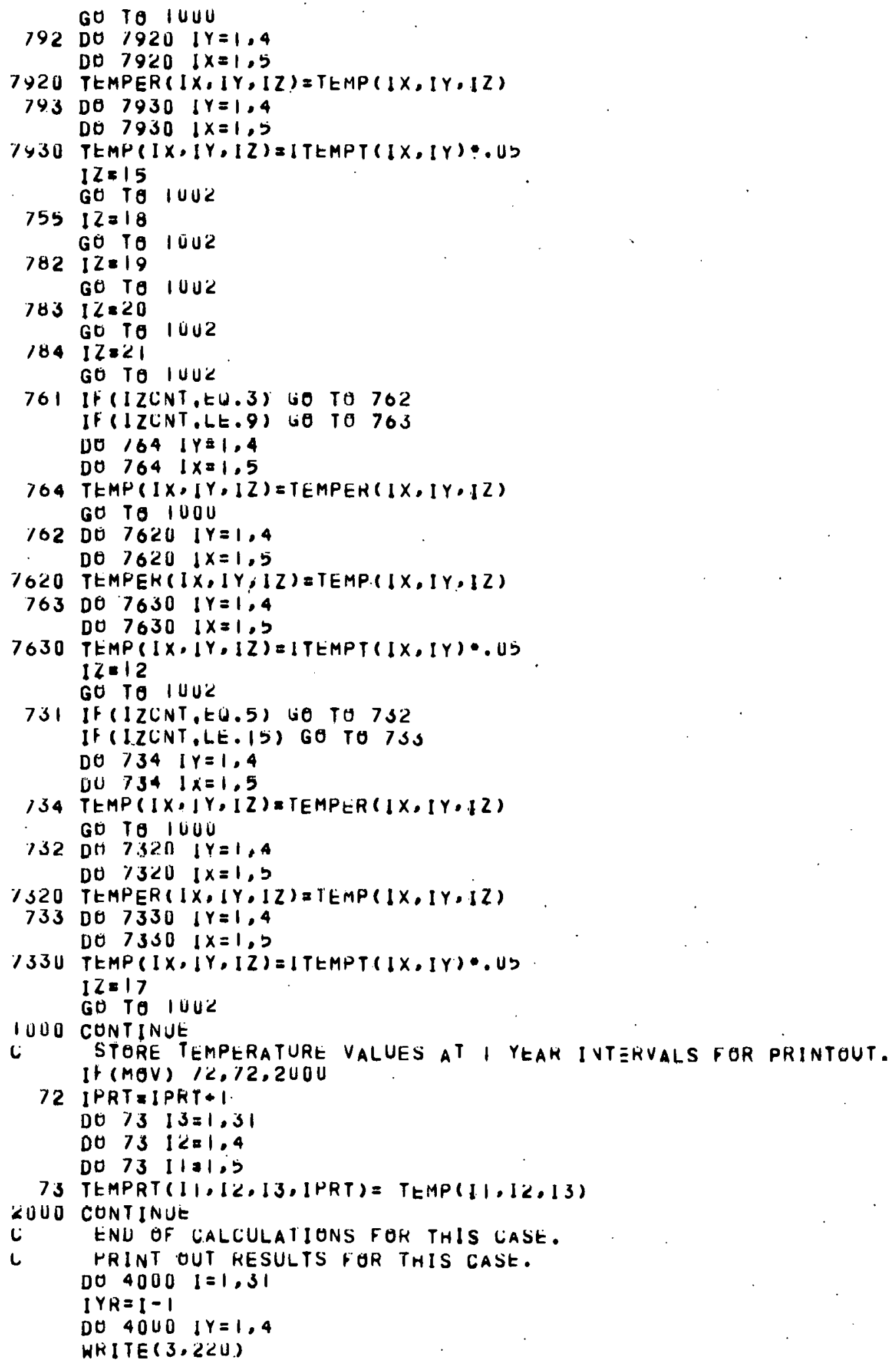




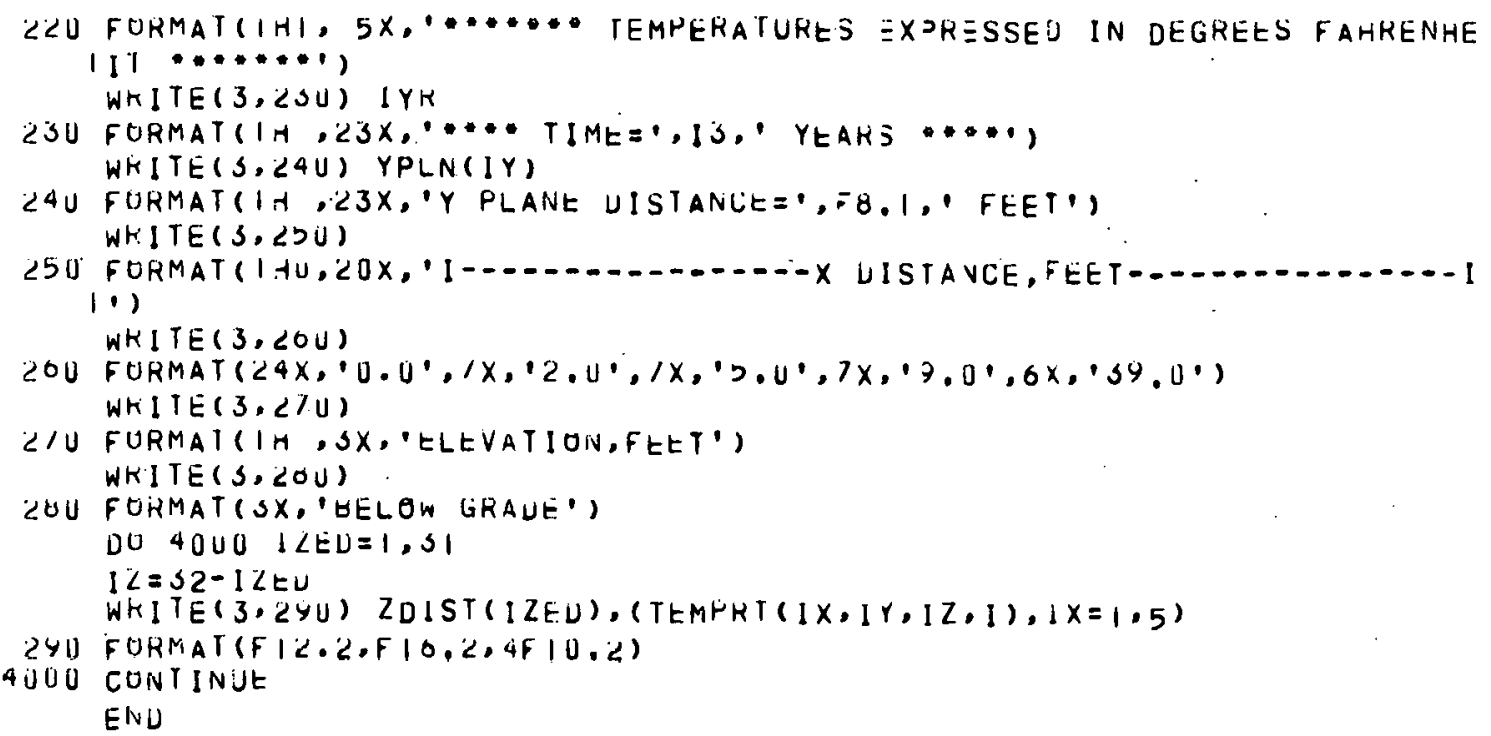


THIS PAGE

\section{WAS INTENTIONALLY \\ LEFT BLANK}


APPENDIX B

DATA INCLUDED IN STORI FILE 


\section{THIS PAGE}

\section{WAS INTENTIONALLY \\ LEFT BLANK}


Appendix B

Data Included in "STORI" File

Variable

NDAC

NPOT

NADC

NAMP

$\operatorname{IAD}(\mathrm{JD}), \operatorname{IVD}(\mathrm{JD}), \mathrm{JD}=1, \mathrm{NDAC}$

$\operatorname{IAP}(\mathrm{JP}), \operatorname{IVP}(\mathrm{JP}), \mathrm{JP}=1, \mathrm{NPOT}$

IAMP

TEMP

GUP

GDN

GX

GY

YPLU

ZDIST
Format

I6

I6

I6

I6

I6

I6

I6

F8. 2

F10.5

F10.5

F10.5

$F 10.3$

F8. 2

F8.2
Váriable Description

Number of digital coefficient units used

Number of servo-set potentiometers used

Number of analog-to-digital conversion channels used

Number of analog amplifiers used

Digital coefficient unit address and value

Servo-set potentiometer address and value

Analog amplifier address

Node temperature

Geometry factor in upward $\mathrm{Z}$ direction

Geometry factor in downward $\mathrm{Z}$ direction

Geometry factor in $\mathrm{X}$ direction

Geometry factor in Y direction

Y plane number

Elevation, in feet 
THIS PAGE

WAS INTENTIONALLY

LEFT BLANK 
ORNL/TM-6355

INTERNAL DISTRIBUTION

1. S. J. Ball

2. A. L. Boch

3. R. S. Booth

4-8. ก. W. Burke

9. W. A. Burnett

10. H. C. Claiborne

11. N. E. Clapp, Jr.

12. F, H. Clark.

13. S. J. Ditto

14. H. N. Hill

15. R. A. Just

16. G. H. Llewellyn

17. B. F. Maskewitz

18. L. L. McCauley

19-28. L. L. McCauley (OWI Records)
29. W. C. McClain

30. J. M. Morrison

31. L: C. Oakes

32. A. S. Quist

33. J. E. Russe1.1.

34. G. S. Sadowski

35. 0. L. Smith

36-40. R. S. Stone

41. C. D. Zerby

42-43: Central Research Library

44. Document Reference Section

45-47. Laboratory Records Department

48. Laboratory Records, ORNL R.C.

49. ORNL Patent office

\section{EXTERNAL DISTRIBUTION}

50-51. J. J. Schreiber, ORO

52-53. R. L. Standerfer, RLO

54-59. J. M. Batch, Battelle Memorial Institute

60-86. Technical Information Center

87. Research and Technical Support Division, ORO 